\title{
Integridade biótica de um córrego na bacia do Alto Rio Paraná avaliada por meio da comunidade de peixes
}

\author{
Cristiane de Paula Ferreira ${ }^{1,2}$ \& Lilian Casatti ${ }^{1}$
}

Biota Neotropica v6 (n3) -http://www.biotaneotropica.org.br/v6n3/pt/abstract?article+bn00306032006

Recebido em 15/03/06

Versão reformulada 20/07/06.

Publicado em 01/09/06.

1. UNESP - Universidade Estadual Paulista, Laboratório de Ictiologia, Departamento de Zoologia e Botânica, IBILCE (www.ibilce.unesp.br), Rua Cristóvão Colombo, 2265, 15054-000, São José do Rio Preto, SP, Brasil. E-mail: cristianebio@gmail.com, lcasatti@ibilce.unesp.br

2. Autor para correspondência: Cristiane de Paula Ferreira, e-mail: cristianebio@gmail.com

\begin{abstract}
Ferreira, C.P. and Casatti, L. Stream biotic integrity assessed by fish assemblages in the Upper Rio Paraná basin. Biota Neotrop. Sep/Dec 2006 vol. 6, no. 3 http://www.biotaneotropica.org.br/v6n3/pt/abstract?article+bn00306032006 ISSN $1676-0603$
\end{abstract}

The state of conservation of the Córrego da Água Limpa, an important water supply for the Monte Aprazível city in the northwestern portion of the São Paulo State, was evaluated. Attributes were selected to compose the fish index of biotic integrity (IBI), aiming to establish a long term monitoring analysis protocol for that basin. The IBI of four equidistant sites along the stream was calculated using two sampling protocols and during dry and wet periods. Biological attributes comparisons were carried out based on the reference scenarios, following a site-specific approach. Few influences of the sampling protocols and seasonality were detected in the IBI final values. Sites 1 and 4 showed fair IBI, site 2 was considered poor and site 3 very poor; such results agree with aspects of the physical habitat quality.

Key words: streams, ichthyofauna, IBI, northwestern São Paulo, biomonitoring

\section{Resumo}

Ferreira, C.P. and Casatti, L. Integridade biótica de um córrego na bacia do Alto Rio Paraná avaliada por meio da comunidade de peixes. Biota Neotrop. Sep/Dec 2006 vol. 6, no. 3 http://www.biotaneotropica.org.br/v6n3/pt/ abstract?article+bn00306032006 ISSN 1676-0603

Neste estudo avaliamos o estado de conservação do Córrego da Água Limpa, uma importante fonte de abastecimento de água para a cidade de Monte Aprazível no noroeste do Estado de São Paulo. Atributos da comunidade de peixes foram selecionados para compor um índice de integridade biótica (IBI), visando gerar um protocolo para monitoramento daquela micro-bacia. O IBI de quatro trechos eqüidistantes ao longo do riacho foi calculado para dois protocolos de amostragem e nos períodos seco e chuvoso. As comparações de atributos selecionados foram realizadas com base em cenários referência, seguindo uma abordagem sítio-específico. Houve pouca influência do esforço de amostragem e da sazonalidade nos valores finais do IBI. De modo geral, os trechos 1 e 4 apresentaram integridade biótica regular, o trecho 2 foi considerado pobre e o trecho 3, muito pobre; tais resultados coincidem com aspectos da qualidade física do hábitat.

Palavras-chave: riachos, ictiofauna, IBI, noroeste paulista, biomonitoramento

http://www.biotaneotropica.org.br 


\section{Introdução}

Os impactos que as ações antrópicas causam aos ambientes lóticos levam à perda de qualidade e dificultam a manutenção da integridade desses ecossistemas, além de interferir na sustentabilidade de suas comunidades (Karr \& Schlosser 1978, Karr \& Dudley 1981, Allan \& Flecker 1993, Karr 1999). Embora seja comum o emprego de critérios químicos para detectar os danos causados aos ambientes aquáticos, avaliações dessa natureza geralmente subestimam a real magnitude desses danos (Karr \& Chu 1999). As abordagens mais recentes de avaliação da qualidade da água empregam descritores físicos e químicos da água e informações sobre a biota aquática em diferentes níveis de organização. Além disso, a estrutura física do hábitat também deve ser considerada na avaliação da qualidade desses ecossistemas, pois influenciam na estrutura e composição das comunidades biológicas, notavelmente peixes (Gorman \& Karr 1978) e macroinvertebrados bentônicos (Callisto et al. 2001).

$\mathrm{O}$ índice de integridade biológica ou biótica (doravante IBI) foi proposto por Karr (1981) para investigar o estado de conservação de riachos nos Estados Unidos utilizando, para isso, atributos observados em comunidades de peixes. Tais atributos devem representar a ampla diversidade ecológica existente e os diversos níveis de organização biológica, e devem ser comparados com condições referência, definidas como aquelas que possuem a menor influência antrópica possível em uma dada região (Hughes 1995). Apesar de algumas limitações, este índice é considerado adequado para identificar a capacidade do ambiente em manter uma comunidade de espécies, com diversidade e organização funcional comparáveis àquelas registradas em áreas minimamente impactadas (TejerinaGarro et al. 2005).

Baseados no trabalho pioneiro de Karr (1981), o IBI utilizando comunidades de peixes foi adaptado para diversas regiões do mundo, tais como América do Norte (Karr 1981, Angermeier \& Karr 1986, Miller et al. 1988), Europa(Oberdorff \& Hughes 1992, Angermeier \& Davideanu 2004), América Central (Lyons et al. 1995), Índia (Ganasan \& Hughes 1998), África (Kamdem Toham \& Teugels 1999), Brasil (Araújo et al. 2003, Bozzetti \& Schulz 2004, Terra 2004) e Nova Zelândia (Joy \& Death 2004). Adaptações foram feitas para ambientes marinhos (Jameson et al. 2001), estuarinos (Weisberg et al. 1997), lacustres (Karr \& Dionne 1991) e terrestres (Kimberling et al. 2001), como também para incorporar outros elementos da biota aquática, tais como macroinvertebrados bentônicos (Kerans \& Karr 1994, Stribling et al. 1998), algas (Hill et al. 2000) e anfíbios (Micacchion 2002).

Apesar da expansão e aplicação em vários sistemas ecológicos, são escassos estudos onde o IBI é interpretado em associação com descritores de qualidade química da água e de integridade física do hábitat ou ainda com aspectos da paisagem e da história de uso da terra (Oberdorff et al. 2002), com exceção de alguns estudos produzidos na América do Norte (Roth et al. 1996, Stauffer et al. 2000), Europa (Angermeier \& Davideanu 2004) e Brasil (Araújo et al. 2003, Bozzetti \& Schulz 2004).

Na região noroeste do Estado de São Paulo restam apenas 3,3 \% de vegetação natural (SMA/IF 2005), dispostos em pequenos fragmentos (a maioria com até 10 ha), o que a caracteriza como uma das mais degradadas áreas do Estado. Na bacia do Rio São José dos Dourados, o Córrego da Água Limpa é a principal fonte de abastecimento para a cidade de Monte Aprazível e, em razão de tal importância, foi implementado um plano de recuperação de suas matas ciliares, com a coordenação do Ministério Público de Monte Aprazível e participação da CATI (Coordenadoria de Assistência Técnica e Integral) e do $4^{\circ}$ Batalhão da Polícia Ambiental do Estado de São Paulo.

O presente estudo teve o objetivo de avaliar o estado de conservação do Córrego da Água Limpa, por meio da adaptação de um índice de integridade biótica empregando características da ictiofauna, passível de ser utilizado para monitorar em longo prazo os efeitos do plano de recuperação das matas ciliares recentemente implementado nesta micro-bacia. Investigamos ainda o efeito de diferentes esforços de amostragens e a influência da sazonalidade no valor do IBI para cada trecho.

\section{Material e métodos \\ Área de estudo}

O riacho estudado é o Córrego da Água Limpa, um afluente da margem esquerda do Rio São José dos Dourados (Figura 1), uma das principais bacias de drenagem da região noroeste do Estado de São Paulo. Da área total da microbacia do Córrego da Água Limpa (7.384 ha), 64\% são utilizados para pastagens e 59\% são considerados muito susceptíveis à erosão (A. M. da Silva dados não publicados). Ao longo de seu curso de aproximadamente $16 \mathrm{~km}$ até a cidade de Monte Aprazível, foram selecionados quatro trechos eqüidistantes, de hierarquia fluvial crescente, cuja descrição detalhada é apresentada por Ferreira \& Casatti (2006).

\section{Coleta de peixes e análise dos conteúdos estomacais}

Foram aplicados dois protocolos amostrais para verificar a influência de diferentes esforços de coletas e da sazonalidade no cálculo do IBI. Um dos protocolos (doravante Protocolo 1) foi aplicado em abril de 2004, utilizando-se de duas passagens de pesca elétrica em 75 metros de extensão em cada trecho, bloqueado nos limites jusante e montante, de acordo com metodologia modificada a partir de Mazzoni et al. (2000) e Castro et al. (2003). Em um segundo protocolo (doravante Protocolo 2) foi aplicada uma passagem de pesca elétrica em 60 metros de extensão em cada trecho, nos três principais meses dos períodos seco (julho, agosto e setembro de 2004) e chuvoso (janeiro, fevereiro e março de 2005), totalizando seis amostragens em cada trecho. Em ambos os 

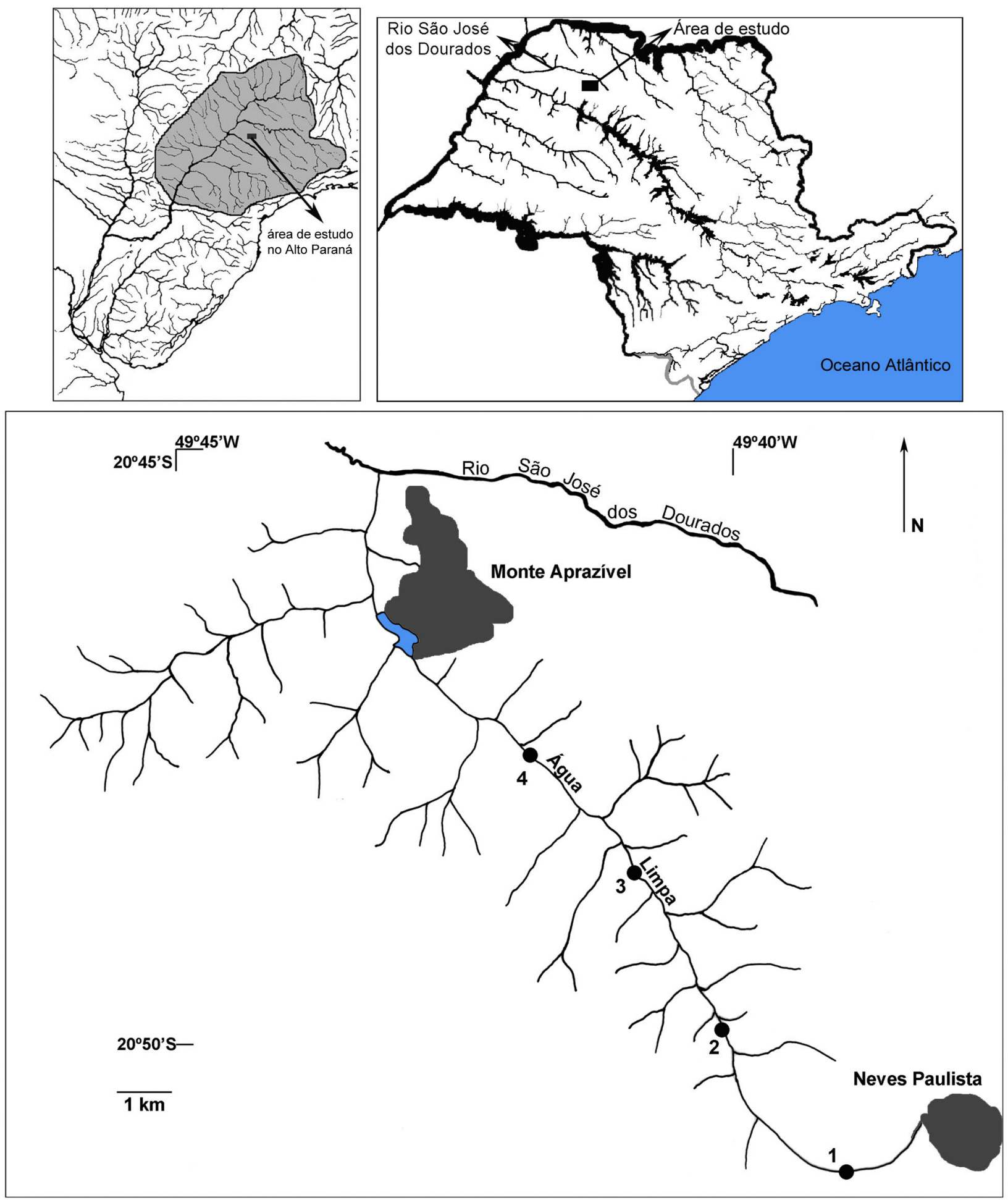

Figura 1. Localização da área de estudo no sistema do Alto Rio Paraná e no Estado de São Paulo, sudeste do Brasil (acima) e os trechos estudados (1-4) ao longo do Córrego da Água Limpa, mostrando sua proximidade com as cidades de Neves Paulista e Monte Aprazível (abaixo). Figure 1. Location of the study area in the Alto Rio Paraná system and in the São Paulo State, southeastern Brazil (above) and the studied stretches (1-4) along the Córrego da Água Limpa, showing their proximity with the cities of Neves Paulista and Monte Aprazivel (below). 
protocolos, os exemplares capturados foram fixados em solução de formalina a $10 \%$ e, após 36 horas, em média, transferidos para solução de EtOH a 70\%. Os exemplares foram depositados na Coleção de Peixes do Departamento de Zoologia e Botânica (DZSJRP 8038-8312), Universidade Estadual Paulista, São José do Rio Preto, Brasil.

Com a finalidade de identificar atributos de natureza trófica, foi analisada a dieta de todas as espécies coletadas com o Protocolo 2. Para cada item alimentar encontrado nos conteúdos gástricos foi calculada a freqüência de ocorrência (Gelwick \& Matthews 1996) e a dominância (Frost \& Went 1940 apud Hynes 1950), esta dada como a porcentagem do número de vezes em que o item ocupa a maior parte do conteúdo de cada estômago em função do número total de exemplares analisados. Os grupos tróficos de cada espécie (com mais que cinco indivíduos coletados, possuindo conteúdo estomacal) foram determinados a partir da identificação dos itens mais dominantes e freqüentes; para tal, a dominância (eixo y) de cada item foi plotada em função da freqüência de ocorrência (eixo x), segundo a proposta de Bennemann et al. (2006), que consiste em uma adaptação do método gráfico de Costello (1990).

\section{Composição do cenário referência para cada trecho e seleção de atributos biológicos}

Um cenário referência deveria representar as condições existentes numa época anterior à intensa ocupação dos continentes pelo homem, o que é praticamente impossível. Assim, idealmente um cenário referência deveria ser determinado com base em condições observadas em áreas que sofreram a menor interferência antrópica possível, tanto em escala regional quanto sítio-específico (Hughes 1995). Além disso, para se avaliar os reais danos antrópicos causados aos ambientes aquáticos, são necessárias adaptações em atributos já utilizados ou elaboração de novos atributos, de acordo com as características fisiográficas da região e da biota local (Tejerina-Garro et al. 2005). No presente estudo foi adotada a abordagem sítio-específico, visto que cada trecho possui fisionomias diferenciadas, o que tornaria impraticável aplicar um mesmo cenário referência para aferir a integridade biótica de todos os trechos e, de acordo com as características de cada trecho e da composição da ictiofauna, alguns atributos consagrados na literatura foram adaptados e outros novos foram propostos.

Para compor o cenário referência do trecho 1 do Córrego da Água Limpa ( $1^{\text {a }}$ ordem) foram utilizadas informações de estudos realizados em áreas de referência na bacia do Alto Rio Paraná (Casatti 2002, 2003, 2005, Casatti et al. 2001, Castro et al. 2003) e foram selecionadas nove métricas com poder de discriminar riachos referência daqueles impactados (Lilian Casatti, estudo em preparação). A determinação de cenários referência para os demais trechos foi prejudicada em razão da escassez de áreas de referência comparáveis, do longo histórico de degradação da região (há pelo menos 100 anos, segundo Monbeig 1998) e da falta de conhecimento sobre o histórico de uso do solo, que dificulta ainda mais a determinação da magnitude dos danos ocasionados (Harding et al. 1998). Assim, os cenários referência para trechos de segunda a quarta ordem foram compostos a partir da combinação de informações publicadas, dados da coleção científica do Departamento de Zoologia e Botânica (DZSJRP) do Instituto de Biociências, Letras e Ciências Exatas (UNESP campus de São José do Rio Preto) e experiência de campo dos autores E importante salientar que o conjunto de atributos biológicos para os trechos de segunda a quarta ordem são de natureza qualitativa, e sua validação está condicionada à realização de testes adicionais.

O cenário referência para o trecho 2 foi adaptado a partir do estudo de Castro \& Casatti (1997), no qual foram analisadas características bióticas e abióticas de um riacho afluente do Rio Pardo, que naquela época corria dentro de um dos raros fragmentos íntegros da região norte do Estado de São Paulo (Tabela 1). Para o trecho 3 foi utilizado o trabalho de Stopiglia (2001), desenvolvido na porção florestada do Ribeirão Bonito, localizada no parque Estadual Morro do Diabo, município de Teodoro Sampaio (Tabela 1). O cenário referência para o trecho 4 foi elaborado com base em coletas realizadas por Valdener Garutti no Córrego da Barra Funda, município de São José do Rio Preto, durante o período seco de 1980 (Tabela 1), e tais informações foram obtidas perante consulta à Coleção de Peixes do Departamento de Zoologia e Botânica (também disponível em http://www.splink.org.br).

\section{Pontuação dos atributos}

Após definir o conjunto de atributos que melhor discrimina os riachos referência daqueles impactados, foram estabelecidos o escore superior e inferior para cada atributo. O escore superior representa $75 \%$ ou mais da condição encontrada nas referências; o escore inferior corresponde a $25 \%$ ou menos da condição encontrada nas referências (Schleiger 2000). Ao primeiro caso é dada a nota 5; ao segundo caso, nota 1; condições intermediárias, ou seja, entre 75 e $25 \%$ das encontradas nas referências, recebem nota 3 . Tais valores foram adaptados a partir do estudo de Roth et al. (1999), onde os autores delimitam os escores extremos como 50 e 10\%. O IBI para cada trecho foi determinado a partir do cálculo da média dos escores de todos os atributos e classificado em uma das quatro categorias de integridade biótica (Tabela 2).

\section{Resultados e Discussão}

Com o Protocolo 1foram coletadas 22 espécies, totalizando 338 indivíduos (Tabela 3), e com o Protocolo 2 foram coletadas 27 espécies e 1.241 indivíduos, dos quais $563(45,4 \%)$ no período seco e $678(54,6 \%)$ no período chuvoso (Tabela 3 ). Os grupos tróficos (Tabela 4) foram determinados para aquelas espécies com pelo menos cinco indivíduos coletados com o Protocolo 2 (Figuras 2 a 4). No caso de espécies com menos de cinco indivíduos coletados, foram mencionados apenas os itens mais abundantes nos conteúdos gástricos (Tabela 4). 


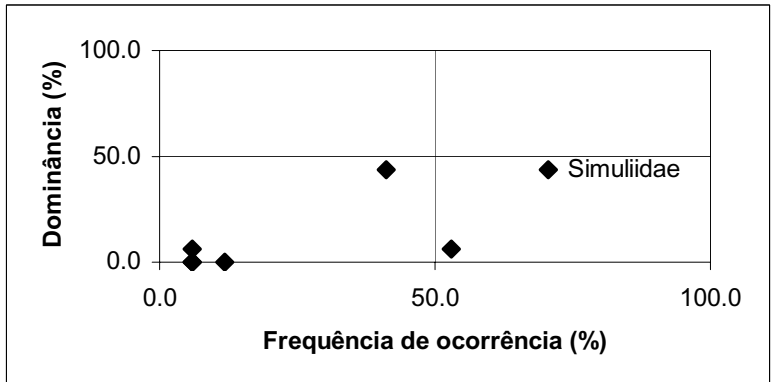

Aspidoras fuscoguttatus $(\mathrm{n}=16)$

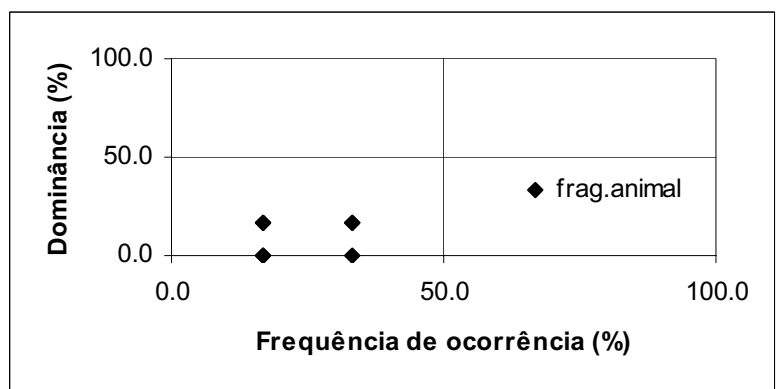

Callichthys callichthys $(\mathrm{n}=6)$

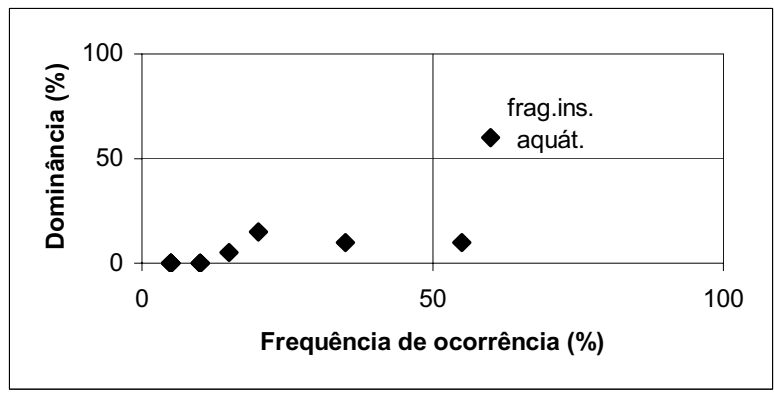

Crenicichla britskï $(\mathrm{n}=20)$

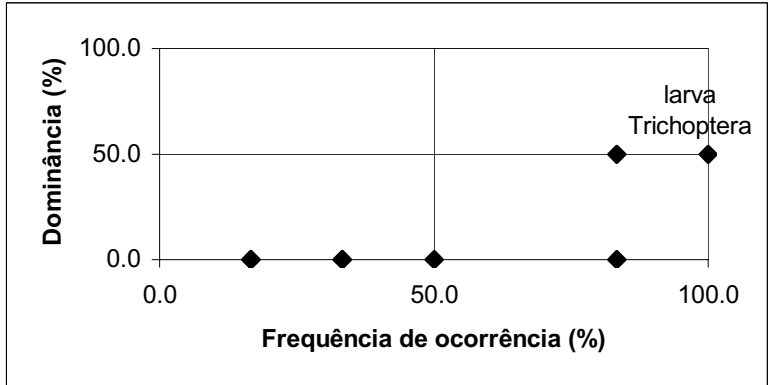

Eigenmannia virescens $(\mathrm{n}=6)$

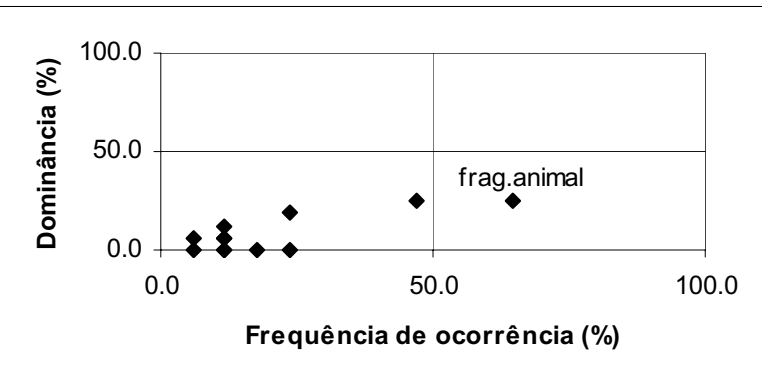

Astyanax altiparanae $(\mathrm{n}=16)$

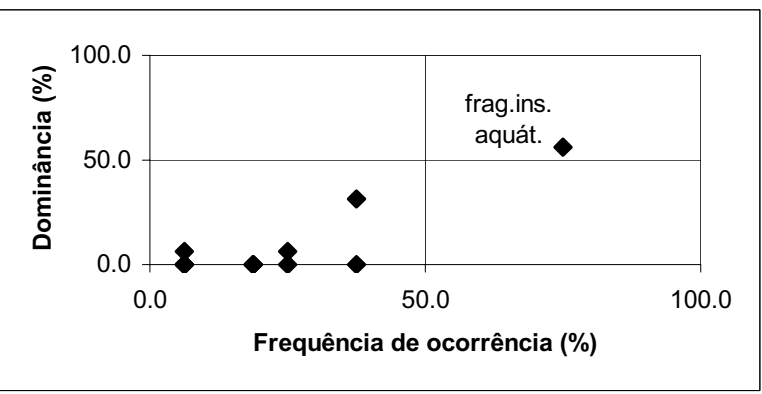

Corydoras aeneus $(\mathrm{n}=16)$

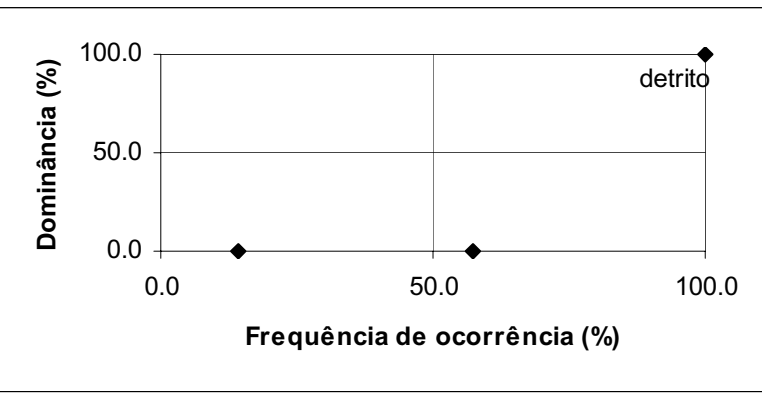

Cyphocharax vanderi $(\mathrm{n}=7)$

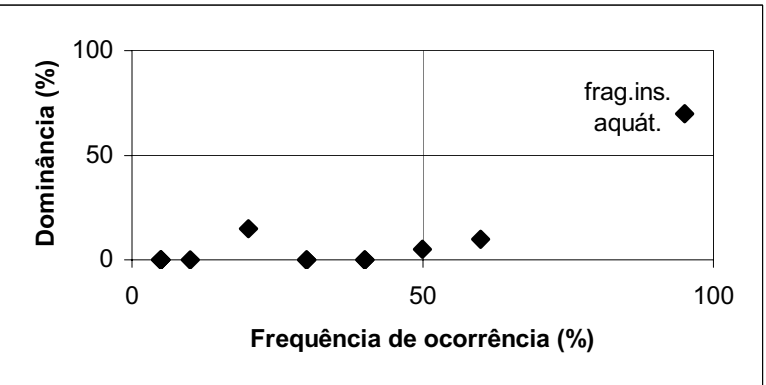

Gymnotus carapo $(\mathrm{n}=20)$

Figura 2. Representação gráfica da dominância (eixo y) e freqüência de ocorrência (eixo x) dos itens alimentares encontrados nos conteúdos gástricos de Aspidoras fuscoguttatus, Astyanax altiparanae, Callichthys callichthys, Corydoras aeneus, Crenicichla britskii, Cyphocharax vanderi, Eigenmannia virescens e Gymnotus carapo no Córrego da Água Limpa. Os números entre parênteses se referem aos indivíduos que continham conteúdo gástrico.

Figure 2. Graphic representation of the dominance (axis $y$ ) and frequency of occurrence (axis $x$ ) of the feeding items registered in the gastric contents of Aspidoras fuscoguttatus, Astyanax altiparanae, Callichthys callichthys, Corydoras aeneus, Crenicichla britskii, Cyphocharax vanderi, Eigenmannia virescens and Gymnotus carapo from the Córrego da Água Limpa. The numbers between parentheses means the number of examined specimens with gastric contents.

http://www.biotaneotropica.org.br 


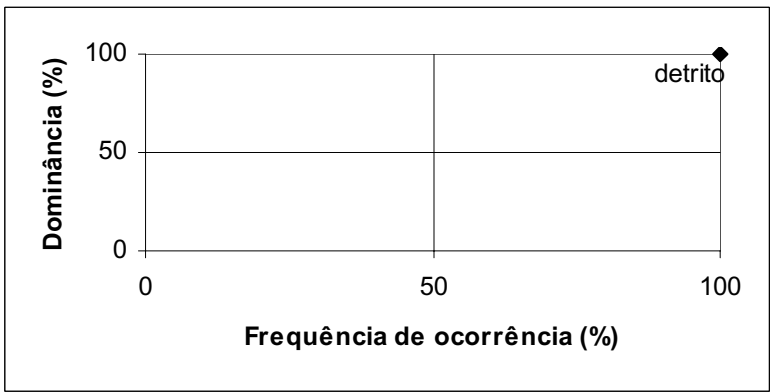

Hisonotus francirochai $(\mathrm{n}=10)$

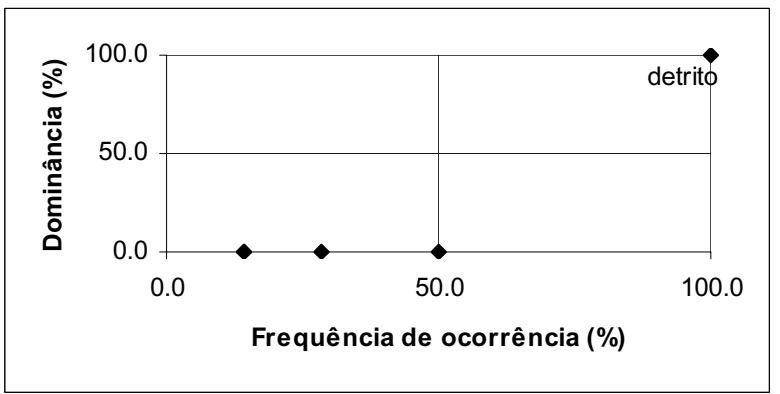

Hypostomus ancistroides $(\mathrm{n}=14)$

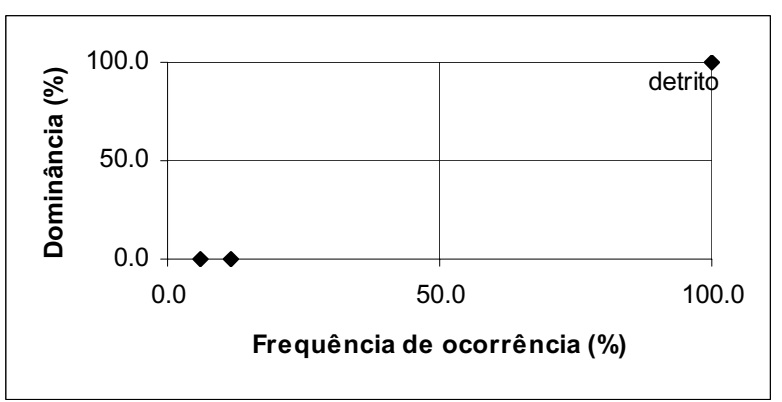

Hypostomus variipictus $(\mathrm{n}=20)$

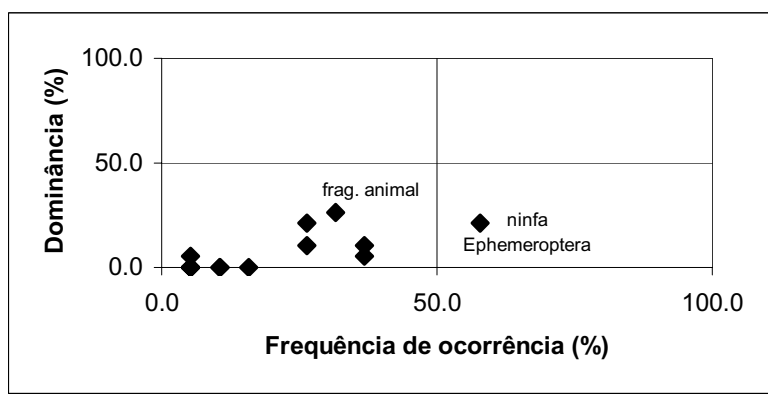

Oligosarcus pintoi $(\mathrm{n}=19)$

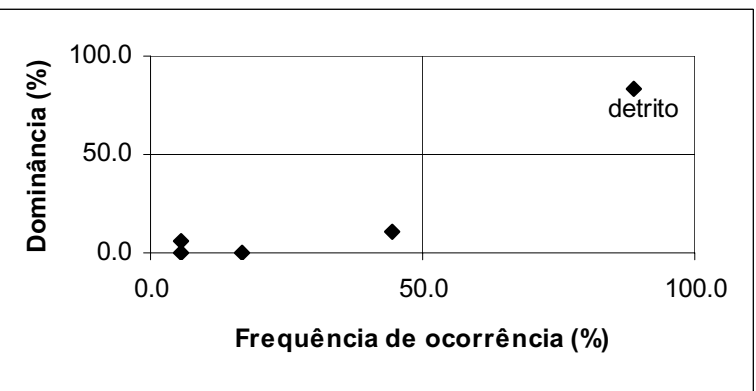

Hisonotus insperatus $(\mathrm{n}=18)$

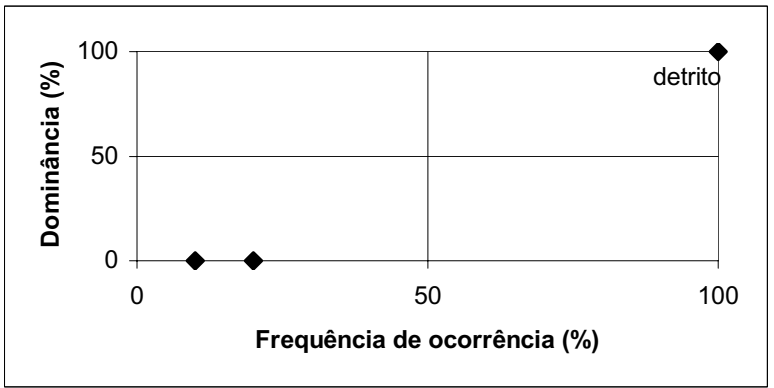

Hypostomus nigromaculatus $(\mathrm{n}=17)$

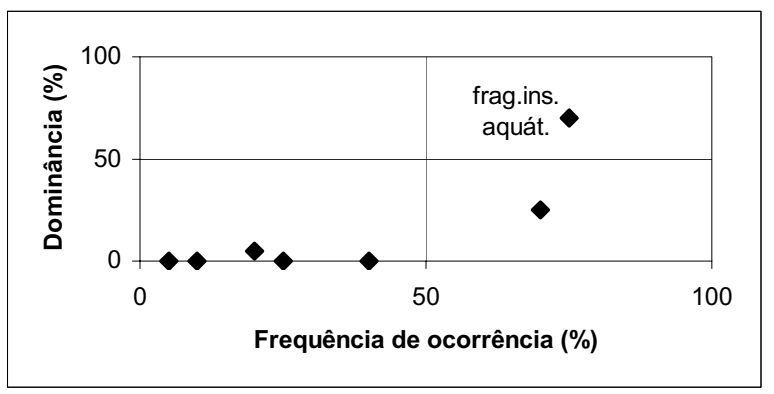

Imparfinis mirini $(\mathrm{n}=20)$

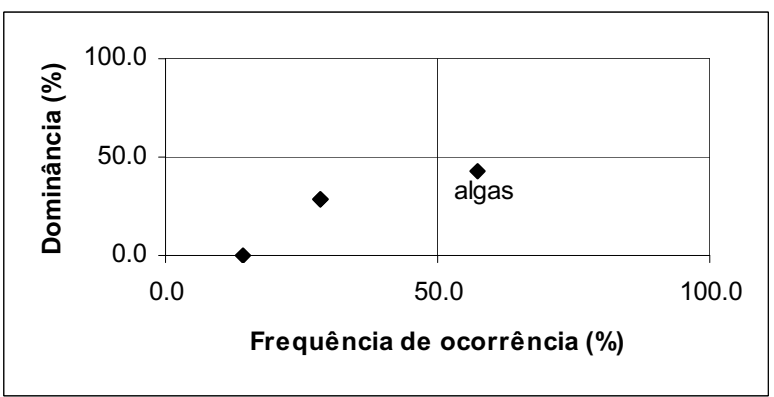

Parodon nasus $(\mathrm{n}=7)$

Figura 3. Representação gráfica da dominância (eixo y) e freqüência de ocorrência (eixo x) dos itens alimentares encontrados nos conteúdos gástricos de Hisonotus francirochai, H. insperatus, Hypostomus ancistroides, H. nigromaculatus, H. variipictus, Imparfinis mirini, Oligosarcus pintoi e Parodon nasus no Córrego da Água Limpa. Os números entre parênteses se referem aos indivíduos que continham conteúdo gástrico Figure 3. Graphic representation of the dominance (axis y) and frequency of occurrence (axis $x$ ) of the feeding items registered in the gastric contents of Hisonotus francirochai, H. insperatus, Hypostomus ancistroides, H. nigromaculatus, H. variipictus, Imparfinis mirini, Oligosarcus pintoi and Parodon nasus from the Córrego da Água Limpa. The numbers between parentheses means the number of examined specimens with gastric contents. 


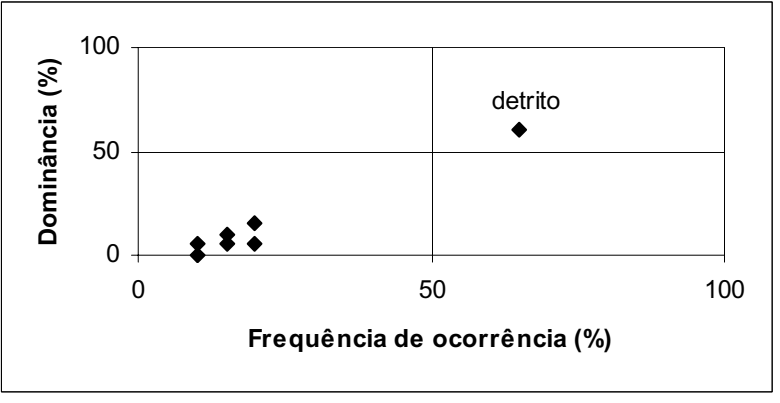

Phalloceros caudimaculatus $(\mathrm{n}=20)$

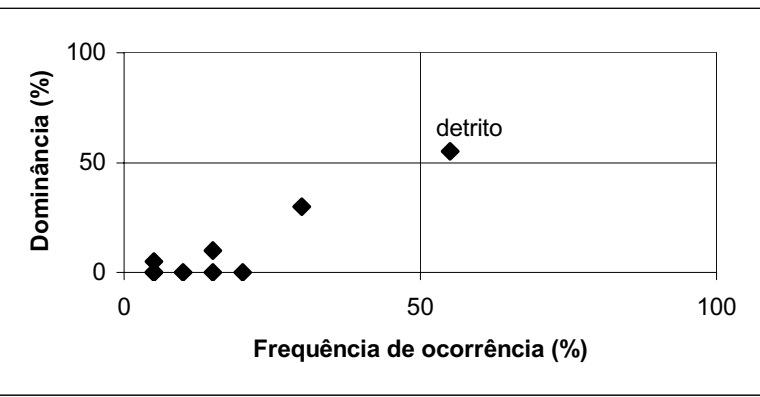

Poecilia reticulata $(\mathrm{n}=20)$

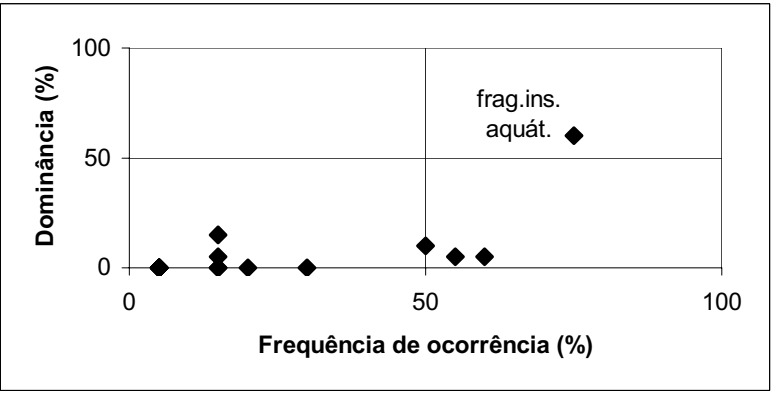

Piabina argentea $(\mathrm{n}=20)$

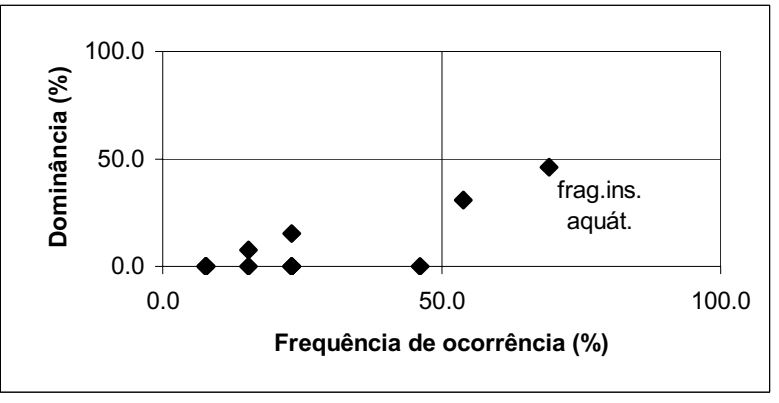

Rhamdia quelen $(\mathrm{n}=13)$

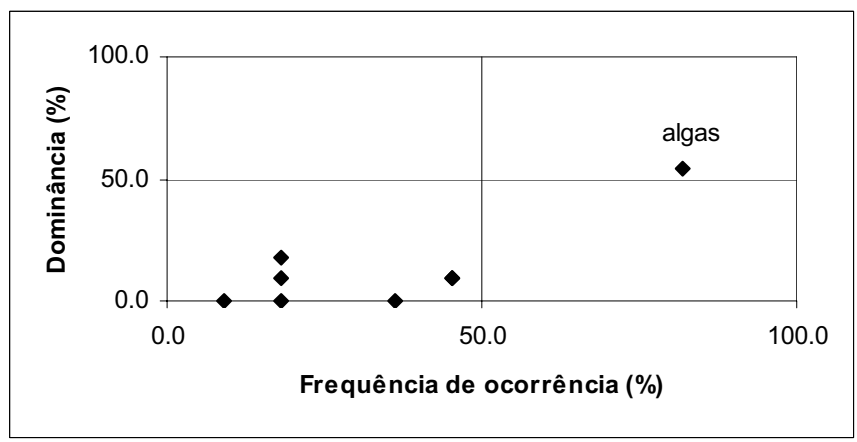

Serrapinnus notomelas $(\mathrm{n}=11)$

Figura 4. Representação gráfica da dominância (eixo y) e freqüência de ocorrência (eixo x) dos itens alimentares encontrados nos conteúdos gástricos de Phalloceros caudimaculatus, Piabina argentea, Poecilia reticulata, Rhamdia quelen e Serrapinnus notomelas no Córrego da Água Limpa. Os números entre parênteses se referem aos indivíduos que continham conteúdo gástrico.

Figure 4. Graphic representation of the dominance (axis y) and frequency of occurrence (axis $x$ ) of the feeding items registered in the gastric contents of Phalloceros caudimaculatus, Piabina argentea, Poecilia reticulata, Rhamdia quelen $e$ Serrapinnus notomelas from the Córrego da Água Limpa. The numbers between parentheses means the number of examined specimens with gastric contents. 


\section{Análise dos atributos biológicos para cada trecho}

Todos os atributos considerados quali ou quantitativamente consistentes para responder aos impactos antrópicos impostos ao Córrego da Água Limpa estão mencionados na Tabela 5. Os valores dos atributos dos trechos estudados no Córrego da Água Limpa, baseados no cenário referência adaptado para cada um deles, e seus respectivos escores estão listados nas Tabelas 6 a 9.

Os atributos “número de espécies nativas” e "número de categorias tróficas" foram adaptados a cada trecho, visto que a riqueza e complexidade trófica tendem a aumentar conforme a hierarquia fluvial (Barreto \& Uieda 1998, Casatti 2005, Braga \& Andrade 2005). Os valores para os atributos "percentual de indivíduos tolerantes”, "percentual de abundância de Poecilia reticulata" e "percentual de riqueza de Characiformes e Siluriformes" foram os mesmos atribuídos aos trechos de primeira ordem, visto que refletem padrões gerais encontrados em riachos de regiões pouco impactadas na bacia do Alto Rio Paraná (Böhlke et al. 1978, Lowe-McConnell 1987, Menezes 1996, Castro \& Menezes 1998).

\section{Avaliação da integridade biótica}

\section{Comparação entre diferentes protocolos de amostragem}

O IBI obtido por meio dos dois protocolos de amostragem foi semelhante para cada trecho (Tabelas 10 a 13). Houve pequenas variações quanto aos escores de alguns atributos, com pouca influência na nota final. Assim, para riachos de baixa ordem, é possível obter dados consistentes para análises de integridade biótica da ictiofauna empregando um menor esforço de coleta (Protocolo 1), onde foram aplicadas duas passagens de pesca elétrica em 75 metros de extensão em uma única ocasião.

Dentre os estudos realizados com o propósito de adequar IBIs utilizando atributos da ictiofauna em riachos, há grande variação entre os esforços amostrais estabelecidos em função da largura e profundidade do riacho. Em geral são empregados protocolos amostrais capazes de explorar uma amostra representativa de hábitats presentes no local (p. ex., Karr 1981), podendo variar de duas passagens de pesca elétrica em 75 metros de extensão (Roth et al. 1999), uma passagem de pesca elétrica em 93 metros (Schleiger 2000) ou ainda três passagens de pesca elétrica em 100-150 metros (Bozzetti \& Schulz 2004). Apesar da pesca elétrica se mostrar um método eficiente para coletar peixes em riachos de baixa ordem, vários fatores podem afetar sua eficiência, dentre os quais condutividade, turbidez, flutuações sazonais, velocidade da corrente e, principalmente, profundidade e largura do canal (Zalewski \& Cowx 1990).

\section{Comparação entre os períodos do ano}

Foi calculado o IBI entre os períodos do ano, utilizando dados obtidos com o Protocolo 2 de amostragem. Foi observada menor integridade no trecho 2 no período seco, sendo que para os demais trechos não houve alteração do valor final do IBI (Tabelas 10 a 13).

Os valores de IBI do Córrego da Água Limpa variaram pouco com relação à sazonalidade. A única mudança de categoria foi referente ao trecho 2 , que passou de pobre no período seco para regular no período chuvoso e pode ser explicada pelos maiores escores dos atributos "percentual de indivíduos tolerantes à hipóxia", "riqueza de espécies nativas" e "riqueza de espécies nectônicas”. Neste caso, a melhoria na qualidade desses atributos pode estar ocasionalmente associada ao recrutamento de espécies de áreas adjacentes devido ao aumento no volume de água. Pouca influência sazonal no IBI também foi registrada por Bozzetti \& Schulz (2004) em riachos do Sul do Brasil. Em locais com maior grau de poluição química, contudo, Araújo (1998a) observou maiores valores de IBI no período seco e menores no período chuvoso, explicando tais resultados pelo maior aporte de material alóctone para dentro dos trechos estudados, diminuindo a qualidade química da água e influenciando negativamente o valor final do IBI.

\section{Comentários Gerais}

Houve pouca alteração da integridade biótica perante diferentes esforços de amostragem e entre os períodos seco e chuvoso (Tabela 14). Por tais razões e para que seja possível comparar os quatro trechos do Córrego da Água Limpa como outros estudos em andamento no noroeste do Estado de São Paulo (L. Casatti dados não publicados), as comparações com condições físicas, químicas e estruturais do hábitat (Tabela 14) foram conduzidas com o IBI calculado para o Protocolo 1 de amostragem.

Paralelamente ao cálculo do IBI de cada trecho, foram também calculados o Índice de Qualidade Química para riachos ("Stream Water Index”, SWI) e o Índice Físico do Hábitat ("Physical Habitat Index”, PHI), seguindo propostas e adaptações de Casatti et al. (2006). Os detalhes das avaliações do SWI e PHI no Córrego da Água Limpa estão apresentados e discutidos por Ferreira \& Casatti (2006). O SWI foi considerado bom para todos os trechos; por outro lado, o PHI foi considerado regular para os trechos 1 e 4 e pobre para os trechos 2 e 3 (Tabela 14).

A integridade da biota aquática pode ser influenciada pela queda na qualidade química da água (Karr 1993), representada tanto pela lavagem dos solos contendo defensivos agrícolas e adubos à base de nitrogênio e fósforo (Brodie \& Mitchell 2005) quanto pela descarga de esgoto doméstico. Tais compostos, quando lançados na água, podem reduzir as concentrações de oxigênio dissolvido que é consumido durante a decomposição das altas quantidades 
de compostos orgânicos e conseqüentemente ocasionar a mortandade de muitas espécies de peixes menos tolerantes a tais condições (Eklöv et al. 1998). Um outro tipo de impacto ocorre em áreas mais urbanizadas, onde indústrias despejam seus efluentes químicos in natura nos rios que correm dentro das cidades, podendo levar ao aparecimento de diversas patologias nos peixes e ao acúmulo de compostos tóxicos ao longo da cadeia trófica, além de eliminar espécies mais sensíveis (DelValls et al. 1998, Eklöv et al. 1998). As condições registradas no Córrego da Água Limpa indicam que a qualidade química da água não influencia diretamente a integridade biótica local. Contudo, as nascentes desse riacho estão localizadas na periferia do município de Neves Paulista, e a manutenção das boas condições registradas depende da prevenção de lançamento inadequado de efluentes domésticos.

Mais interligados, no entanto, foram os resultados da integridade física do hábitat e da integridade biótica de cada trecho. O trecho 1 apresentou integridade física regular, reflexo principalmente da boa diversidade de hábitats (poços, corredores e corredeiras). Tal diversidade de hábitats permite a ocorrência de várias espécies com características biológicas diferenciadas, tais como Astyanax altiparanae e Piabina argentea, espécies nectônicas, que ocupam a coluna d’água; Aspidoras fuscoguttatus e Corydoras aeneus que forrageiam no fundo arenoso; Gymnotus carapo que utiliza os bancos de gramíneas marginais para abrigo e forrageio e Hypostomus nigromaculatus que ocorre nas corredeiras de substrato rochoso. A alta diversidade de espécies e eqüitabilidade possivelmente estão associadas à maior heterogeneidade de hábitats disponíveis (Ferreira \& Casatti 2006). Tais características de estrutura e composição da ictiocenose se refletem no IBI do trecho 1 , que obteve os maiores escores nos atributos "número de espécies nativas”, “número de espécies de corredeiras”, "percentual de espécies reofílicas", "percentual de abundância de $P$. reticulata" e "dominância”.

No trecho 2 o PHI foi considerado pobre, principalmente por ser um corredor único, sem diversidade de hábitats e substrato instável, fatores que favoreceram algumas espécies mais generalistas de hábitos bentônicos em fundo arenoso e, em contraste, inviabilizaram a ocorrência de espécies reofílicas. Tais fatores também foram refletidos no IBI; por exemplo, a abundância de gramíneas nas margens, ao longo de todo trecho, disponibilizam um micro-hábitat que favorece a ocupação de G. carapo, espécie que, sendo dominante no ambiente (Ferreira \& Casatti 2006), contribui como um atributo de influência negativa no IBI. A elevada abundância de $P$. reticulata nesse trecho também colaborou para a queda no resultado final do IBI, pois além de ser uma espécie exótica, está geralmente associada a hábitats simplificados, alimenta-se de uma grande variedade de recursos e possui poucas exigências quanto à disponibilidade de sítios para reprodução (Reznick \& Bryga 1987, Trexler 1988, Oliveira \& Bennemann 2004). A ausência de espécies reofílicas e o baixo percentual de espécies de Characiformes e Siluriformes notadamente influenciaram o baixo valor do IBI neste trecho.

No trecho 3 foi marcante a baixa riqueza de espécies, quando comparado com a condição referência e algumas características físicas podem estar diretamente associadas à baixa integridade biótica encontrada neste trecho. A baixa estabilidade do substrato, elevada turbidez e profundidade deste local podem inviabilizar o estabelecimento do perifíton e, conseqüentemente, a ocorrência de espécies de hábitos perifitívoros, como os parodontídeos e loricariídeos. A ausência de vegetação ripária, também inviabiliza a ocorrência de espécies que se alimentam exclusivamente de material vegetal alóctone, como frutos e sementes. Em razão da ausência dessas várias categorias de espécies, os escores dos atributos "número de espécies nativas”, "percentual de indivíduos perifitívoros”, "número de espécies da família Curimatidae”, “número de espécies de Characiformes frugívoros ou herbívoros alóctones” e “número de espécies piscívoras” receberam pontuação muito baixa ou não foram pontuados, influenciando negativamente a nota final do IBI deste trecho, classificado como muito pobre.

O trecho 4, embora estruturalmente menos heterogêneo do que o trecho 1 em razão da predominância de corredeiras, também mostrou integridade biótica regular. Tal resultado se deve principalmente às características físicas do hábitat que disponibilizam micro-hábitats para diversas espécies de hábitos reofílicos, especialmente Siluriformes, influenciando positivamente o IBI. Além disso, em razão da forte correnteza, não foram registrados microhábitats que seriam utilizados por espécies tolerantes e por $P$. reticulata, contribuindo para que os escores desses atributos fossem altos.

Em síntese, mesmo com o emprego de atributos ainda não testados quantitativamente (trechos 2-4) em razão da urgência no desenvolvimento deste protocolo de monitoramento, ficou evidente que a integridade biótica do Córrego da Água Limpa sofre notável influência da estrutura do hábitat. A combinação de ferramentas de análise que incluem informações físicas, químicas, estruturais do hábitat e biológicas, tal como aplicada neste estudo, permitirá realizar um monitoramento em longo prazo da micro-bacia em questão, empregando pouco tempo de trabalho no campo, baixo custo e rápida liberação de resultados. Finalmente, consideramos fundamental o incentivo à preservação de remanescentes florestais na região e seus corpos d'água, que serão valiosos como áreas comparativas em futuros estudos de biomonitoramento.

\section{Agradecimentos}

Agradecemos à equipe do Laboratório de Ictiologia DZSJRP-IBILCE pelo auxílio no campo; Francisco Langeani pelo auxílio nas identificações taxonômicas dos peixes; 
Alexandre M. Silva pela análise de uso e ocupação do solo da micro-bacia; Departamento de Zoologia e Botânica e Programa de Pós-Graduação em Biologia Animal IBILCEUNESP pelo apoio; IBAMA pela licença de coleta (001/2003); $4^{\circ}$ Batalhão da Polícia Ambiental do Estado de São Paulo pelo auxílio na localização e reconhecimento dos pontos de coleta; Ricardo M. C. Castro, Sirlei T. Bennemann e assessores anônimos por valiosas sugestões. Este trabalho foi financiado pela Fundação de Amparo à Pesquisa do Estado de São Paulo (FAPESP) dentro do Programa BIOTASP/FAPESP - O Instituto Virtual da Biodiversidade (www.biota.org.br) - através do Auxílio à Pesquisa “Avaliação da integridade biótica dos riachos da região noroeste do Estado de São Paulo, bacia do Alto Paraná, utilizando comunidades de peixes” (FAPESPn ${ }^{\circ}$ 01/13340-7). As autoras foram bolsistas da FAPESP (processos $n^{\circ}$ 02/ 05996-2, 03/09612-7).

\section{Referências bibliográficas}

ALLAN, J.D. \& FLECKER, A.S. 1993. Biodiversity conservation in running waters. BioScience 43:32-43.

ANGERMEIER, P.L. \& KARR, J.R. 1986. Applying an index of biotic integrity based on stream-fish communities: considerations in sampling and interpretation. N. Am. J. Fish. Manage. 6:418-429.

ANGERMEIER, P.L. \& DAVIDEANU, G. 2004. Using fish communities to assess streams in Romania: initial development of an index biotic integrity. Hydrobiol. 511:65-78.

ARAÚJO, F.G. 1998a. Adaptação do índice de integridade biótica usando a comunidade de peixes para o Rio Paraíba do Sul. Revta Bras. Zool. 58:547-558.

ARAÚJO, F.G. 1998b. Uso da taxocenose de peixes como indicadora de degradação ambiental no Rio Paraíba do Sul, Rio de Janeiro, Brasil. Braz. Arch. Biol. Technol. 41:370-378.

ARAÚJO, F.G., FICHBERG, I., PINTO, B.C.T. \& PEIXOTO, M.G. 2003. A preliminary index of biotic integrity for monitoring the condition of the Rio Paraíba do Sul, southeast Brazil. Environ. Manage. 32:516-526.

BARRETO, M.G. \& UIEDA, V.S. 1998. Influence of the abiotic factors on the ichthyofauna composition in different orders stretches of Capivara River, São Paulo State, Brazil. Verh. Internat. Verein. Limnol. 26:2180-2183.

BENNEMANN, S.T., CASATTI, L. \& OLIVEIRA, D.C. 2006. Alimentação de peixes: proposta para análise de itens registrados em conteúdos gástricos. Biota Neotrop. 6(2): http://www.biotaneotropica.org.br/v6n2/pt/ abstract?article+bn01206022006

BÖHLKE, J., WEITZMANN, S.H. \& MENEZES, N.A. 1978. Estado atual da sistemática de peixes de água doce da América do Sul. Acta Amaz. 8:657-677.
BOZZETTI, M. \& SCHULZ, U.H. 2004. An index of biotic integrity based on fish assemblages for subtropical streams in southern Brazil. Hydrobiol. 529:133-144.

BRAGA, F.M.S. \& ANDRADE, P.M. 2005. Distribuição de peixes na microbacia do Ribeirão Grande, Serra da Mantiqueira Oriental, São Paulo, Brasil. Iheringia, Ser. Zool. 95:121-126.

BRODIE, J.E. \& MITCHELL, A.W. 2005. Nutrients in Australian tropical rivers: changes with agricultural development and implications for receiving environments. Mar. Fresh. Res. 56:279-302.

CALLISTO, M., MORETTI, M. \& GOULART, M. 2001. Macroinvertebrados bentônicos como ferramenta para avaliar a saúde de riachos. Rev. Bras. Rec. Hídricos 6:71-82.

CASATTI, L. 2002. Alimentação dos peixes em um riacho do Parque Estadual Morro do Diabo, bacia do Alto Rio Paraná, Sudeste do Brasil. Biota Neotrop. 2(2):http:// www.biotaneotropica.org.br/v2n2/pt/ abstract?article+BN02502022002

CASATTI, L. 2003. Biology of a catfish, Trichomycterus sp. (Pisces, Siluriformes), in a pristine stream in the Morro do Diabo State Park, Southeastern Brazil. Stud. Neotrop. Fauna Environ. 38:105-110.

CASATTI, L. 2005. Fish assemblage structure in a first order stream, Southeastern Brazil: longitudinal distribution, seasonality and microhabitat diversity. Biota Neotrop. 5(1):http://www.biotaneotropica.org.br/v5n1/ pt/abstract?article+BN02505012005

CASATTI, L., LANGEANI, F. \& CASTRO, R.M.C. 2001. Peixes de riacho do Parque Estadual Morro do Diabo, bacia do Alto Rio Paraná, SP. Biota Neotrop. 1(1/2):http:/ /www.biotaneotropica.org.br/v1n12/pt/ abstract?inventory+BN00201122001

CASATTI, L., SILVA, A.M., LANGEANI, F. \& CASTRO, R.M.C. 2006. Stream fishes, water and habitat quality in a pasture dominated basin, Southeastern Brazil. Braz. J. Biol. 66:681-696.

CASTRO, R.M.C.\& CASATTI, L. 1997. The fish fauna from a small forest stream of the upper Paraná River basin, southeastern Brazil. Ichthyol. Explor. Freshwaters 7:337-352.

CASTRO, R.M.C. \& MENEZES, N.A. 1998. Estudo diagnóstico da diversidade de peixes do Estado de São Paulo. In Biodiversidade do Estado de São Paulo, Brasil: síntese do conhecimento ao final do século $\mathrm{XX}, 6$, vertebrados (R.M.C. Castro, ed.). WinnerGraph \& FAPESP, São Paulo, p.1-13. 
CASTRO, R.M.C., CASATTI, L., SANTOS, H.F., FERREIRA, K.M., RIBEIRO, A.C., BENINE, R.C., DARGIS, G.Z.P., MELO, A.L.A., STOPIGLIA, R., ABREU, T.X., BOCKMANN, F.A., CARVALHO, M., GIBRAN, F.Z. \& LIMA, F.T.C. 2003. Estrutura e composição da ictiofauna de riachos do Rio Paranapanema, sudeste do Brasil. Biota Neotrop. 3(1):http://www.biotaneotropica.org.br/v3n1/ pt/abstract?article+BN01703012003

COSTELLO, M.J. 1990. Predator feeding strategy and prey importance: a new graphical analysis. J. Fish Biol. 36:261-263.

DELVALLS, T.A., CONRADI, M., GARCIA-ADIEGO, E., FORJA, J.M. \& GÓMEZ-PARRA, A. 1998. Analysis of macrobenthic community structure in relation to different environmental sources of contamination in two littoral ecosystems from the Gulf of Cádiz (SW Spain). Hydrobiol. 385:59-70.

EKLÖV, A.G., GREENBERG, L.A., BRÖNMARK, C., LARSSON, P. \& BERGLUND, O. 1998. Response of stream fish to improved water quality: a comparison between the 1960s and 1990s. Freshwater Biol. 40:771-782.

FERREIRA, C.P. \& CASATTI, L. 2006. Influência da estrutura do hábitat sobre a ictiofauna de um riacho em uma micro-bacia de pastagem, São Paulo, Brasil. Revta Bras. Zool. 23:642-651.

FROST, W.E. \& WENT, A.E.J. 1940. River Liffey survey. III. The growth and food of young salmon. Proc. R. Irish Acad. 46B:53-80.

GANASAN, V. \& HUGHES, R.M. 1998. Application of an index of biological integrity (IBI) to fish assemblages of the rivers Khan and Kshipra (Madhya Pradesh), India. Freshwater Biol. 40:367-83.

GARUTTI, V. 1988. Distribuição longitudinal da ictiofauna em um córrego da região noroeste do Estado de São Paulo, bacia do rio Paraná. Rev. Brasil. Biol., 48:747-759.

GELWICK, F. P. \& MATTHEWS, W. J. 1996. Trophic relations of stream fishes. In Methods in stream ecology (G. Lamberti \& R. Hauer, eds.). Academic Press, New York, p.475-492.

GORMAN, O.T. \& KARR, J.R. 1978. Habitat structure and stream fish communities. Ecology 59:507-515.

HARDING J.S., BENFIELD, E.F., BOLSTAD, P.V., HELFMAN, GS. \& JONES III, E.B.D. 1998. Stream biodiversity: The ghost of land use past. Proc. Nat. Acad. Sci. 95:14843-14847.

HARRIS, J.H. 1995. The use of fish in ecological assessments. Aust. J. Ecol. 20:65-80.

HILL, B.H., HERLIHY, A.T., KAUFFMANN, P.R., STEVERSON, R.J., MCCORMICK, F.H. \& JOHNSON, C.B. 2000. Use of periphyton assemblage data as an index of biotic integrity. J. North Am. Benth. Soc. 19:50-67.

HUGHES R.M. 1995. Defining acceptable biological status by comparing with reference conditions. In Biological assessment and criteria: tools for water resource planning and decision making (W.S. Davis \& T.P. Simon, eds.). CRC Press Inc., Boca Raton, Florida, p.31-47.
HYNES, H.B.N. 1950. The food of fresh-water sticklebacks (Gasterosteus aculeatus and Pygosteus pungitius), with a review of methods used in studies of the food of fishes. J. Anim. Ecol. 19:36-57.

JAMESON, S.C., ERDMANN, M.V., KARR, J.R. \& POTTS, K.W. 2001. Charting a course toward diagnostic monitoring: a continuing review of coral reef attributes and a research strategy for creating coral reef indexes of biotic integrity. B. Mar. Sci. 69:701-44.

JOY, M.K. \& DEATH, R.G. 2004. Application of the index of biotic integrity methodology to New Zealand freshwater fish communities. Environ. Manage. 34:415-428.

KAMDEM TOHAM, A.K. \& TEUGELS, G.G. 1999. First data on an index of biotic integrity (IBI) based on fish assemblages for the assessment of the impact of deforestation in a tropical West African river system. Hydrobiol. 397:29-38.

KARR, J.R. 1981. Assessment of biotic integrity using fish communities. Fisheries 6:21-27.

KARR, J.R. 1993. Measuring biological integrity: lessons from streams. In Ecological integrity and the management of ecosystems (S. Woodley, J. Ray \& G. Francis, eds.). Saint Lucie Press, Ottawa, p.83-103.

KARR, J.R. 1999. Defining and measuring river health. Freshwater Biol. 41:221-234.

KARR, J.R. \& SCHLOSSER, I.J. 1978. Water resources and the land-water interface. Science 201:229-234.

KARR, J.R. \& DUDLEY, D.R. 1981. Ecological perspective on water quality goals. Environ. Manage. 5:55-68.

KARR, J.R. \& DIONNE, M. 1991. Designing surveys to assess biological integrity in lakes and reservoirs. In Biological criteria: research and regulation. U.S. Environmental Protection Agency, Washington D.C., EPA - 440/ 5-91-005, p.62-72.

KARR, J.R. \& CHU, E.W. 1999. Restoring life in running waters: better biological monitoring. Island Press, Washington DC.

KERANS, B.L. \& KARR, J.R. 1994. A benthic index of biotic integrity (B-IBI) for rivers of the Tennesse Valley. Ecol. Appl. 4:768-785.

KIMBERLING, D.N., KARR, J.R. \& FORE, L.S. 2001. Measuring human disturbance using terrestrial invertebrates in the shrubsteppe of eastern Washington(USA). Ecol. Indic. 1:63-81.

LOWE-MCCONNELL, R.H. 1987. Ecologial studies in tropical fish communities. Cambridge University Press, Cambridge.

LYONS, J., NAVARRO-PEREZ, S., COCHRAN, P.A., SANTANA, E. \& GUZMÁN-ARROYO, M. 1995. Index of biotic integrity based on fish assemblages for the conservation of streams and rivers in West-Central México. Conserv. Biol. 9:569-584.

MAZZONI, R., FENERICH-VERANI, N. \& CARAMASCHI, E.P. 2000. Electrofishing as a sampling technique for coastal stream fish populations and communities in the southeast of Brazil. Rev. Brasil. Biol. 60:205-216. 
MENEZES, N. A. 1996. Methods for assessing freshwater fish diversity. In Biodiversity in Brazil (C.E.M. Bicudo \& N.A. Menezes, eds.). CNPq, São Paulo, p.289-295.

MICACCHION, M. 2002. Amphibian index of biotic integrity (AmphIBI) for wetlands. Final Report EPA Grant $\mathrm{n}^{\circ} \mathrm{CD} 985875-01$, Ohio.

MILLER, D.L., LEONARD, P.M., HUGHES, R.M., KARR, J., MOYLE, P.B., SCHRADER, L.H., THOMPSON, B.A., DANIELS, R.A., FAUSCH, K.D., FITZHUGH, G.A., GAMMON, J.R., HALLIWELL, D.B.,ANGERMEIER, P.L. \& ORTH, D.J. 1988. Regional applications of an index of biotic integrity for use in water resource management. Fisheries 13:12-20.

MONBEIG, P. 1998. Pioneiros e fazendeiros de São Paulo. Hucitec, São Paulo.

OBERDORFF, T. \& POCHER, J.P. 1994. An index of biotic integrity to assess biological impacts of salmonid farm effluents on receiving waters. Aquaculture 119:219-235.

OBERDORFF, T. \& HUGHES, R.M. 1992. Modification of an index of biotic integrity based on fish assemblages to characterize rivers of the Seine Basin, France. Hydrobiol. 228:117-30.

OBERDORFF, T., PONT, D., HUGUENY, B. \& PORCHER, J.P. 2002. Development and validation of a fish-based index for the assessment of 'river health' in France. Freshwater Biol. 47:1720-1734.

OLIVEIRA, D.C. \& BENNEMANN, S.T. 2004. Ictiofauna, recursos alimentares e relações com as interferências antrópicas em um riacho urbano no sul do Brasil. Biota Neotrop. 5(1):http://www.biotaneotropica.org.br/v5n1/ pt/abstract?article+BN02905012005

REZNICK, D.N. \& BRYGA, H. 1987. Life-history evolution in guppies (Poecilia reticulata): 1 . Phenotipic and genetic changes in an introduction experiment. Evolution 41:370-1385.

ROTH, N.E., ALLAN, J.D. \& ERICKSON, D.L. 1996. Landscape influences on stream biotic integrity assessed at multiple spatial scales. Landscape Ecol. 11:141-156.

ROTH, N.E., SOUTHERLAND, M.T., MERCURIO, G., CHAILLOU, J.C., KAZYAK, P.F., STRANKO, S.S., PROCHASKA, A.P., HEIMBUCH, D.G. \& SEIBEL, J.C. 1999. State of the streams: 1995-1997 Maryland biological stream survey results. Prepared by Tetra Tech Inc. for the Maryland Department of Natural Resources, Monitoring and Non-Tidal Assessment division, Annapolis, Maryland, CBWP-MANTA - EA-99-6.

SCHLEIGER, S.L. 2000. Use of an index of biotic integrity to detect effects of land uses on stream fish communities in West-Central Georgia. Trans. Am. Fish. Soc. 129:1118-1133.

SMA/IF (Secretaria do Meio Ambiente / Instituto Florestal). 2005. Inventário florestal da vegetação natural do Estado de São Paulo. Imprensa Oficial do Estado de São Paulo, São Paulo.
STAUFFER, J.C., GOLDSTEIN, R.M. \& NEWMAN, R.M. 2000. Relationship of wooded riparian zones and runoff potential to fish community composition in agricultural streams. Can. J. Fish. Aquat. Sci. 57:307-316.

STOPIGLIA, R. 2001. Diversidade e aspectos da biologia de duas comunidades de peixes do Ribeirão Bonito, bacia do Alto Rio Paraná, SP. Monografia de Bacharelado, FFCLRP-USP, Ribeirão Preto.

STRIBLING, J.B., JESSUP, B.J., WHITE, J.S., BOWARD, D. \& HURD, M. 1998. Development of a benthic index of biotic integrity for Maryland streams. Prepared by Tetra Tech Inc. for the Maryland Department of Natural Resources, Monitoring and Non-Tidal Assessment division, Annapolis, Maryland, CBWP-EA-98-3.

TEJERINA-GARRO, F.L., MALDONADO, M., IBAÑEZ, C., PONT, D., ROSET, N. \& OBERDORFF, T. 2005. Effects of natural and anthropogenic environmental changes on riverine fish assemblages: a framework for ecological assessment of rivers. Braz. Arch. Biol. Technol. 48:91-108.

TERRA, L.C.C. 2004. Avaliação da integridade biótica do Rio Formoso e Córrego Bonito, na bacia do Rio Formoso, município de Bonito, Mato Grosso do Sul. Dissertação de Mestrado, UNIDERP, Campo Grande.

TREXLER, J.C. 1988. Phenotypic plasticity in poeciliid life histories. In Ecology and evolution of livebearing fishes (Poeciliidae) (G.K. Meffe \& F.F. Snelson, eds.). Prentice Hall, New Jersey, p.201-214

WEISBERG, S.B., RANASINGHE, J.A., SCHAFFNER, L.C., DIAZ, R.J., DAUER, D.M. \& FRITHSEN, J.B. 1997. An estuarine benthic index of biotic integrity (B-IBI) for Chesapeake Bay. Estuaries 20:149-58.

ZALEWSKI, M. \& COWX, I.G. 1990. Factors affecting the efficiency of electric fishing. In Fishing with electricity - applications in freshwater fisheries management (I.G. Cowx \& P. Lamarque, eds.). Fishing New Books, Oxford, p.89-111.

Título: Integridade biótica de um córrego na bacia do Alto Rio Paraná avaliada por meio da comunidade de peixes.

Autores: Ferreira, C.P. and Casatti, L.

Biota Neotropica, Vol. 6 ( número 3 ): 2006

http://www.biotaneotropica.org.br/v6n3/pt/ abstract?article+bn00306032006

Recebido em 15/03/06 - Versão reformulada 20/07/06 Publicado em 01/09/06.

ISSN 1676-0603 
Tabela 1. Abundância total e relativa de cada espécie registrada no estudo de Castro \& Casatti (1997), utilizado como referência para o trecho 2, e no estudo de Stopiglia (2001), utilizado como referência para o trecho 3. A referência do trecho 4 foi composta com base em exemplares coletados por Valdener Garutti, em 1980, depositados da Coleção de Peixes do Departamento de Zoologia e Botânica (DZSJRP) IBILCE/UNESP.

Table 1. Total and relative abundance of each species registered in the study of Castro \& Casatti (1997), used as reference to site 2, and in the study of Stopiglia (2001), used as reference to site 3. The reference to site 4 was based on fishes sampled by Valdener Garutti, in 1980, deposited in the fish collection of the Departamento de Zoologia e Botânica (DZSJRP) IBILCE/UNESP.

\begin{tabular}{|c|c|c|c|c|c|c|}
\hline \multirow{2}{*}{ Espécies } & \multicolumn{2}{|c|}{ Trecho 2} & \multicolumn{2}{|c|}{ Trecho 3} & \multicolumn{2}{|c|}{ Trecho 4} \\
\hline & $\mathbf{N}$ & $\%$ & $\mathbf{N}$ & $\%$ & $\mathbf{N}$ & $\%$ \\
\hline Aspidoras fuscoguttatus & - & - & - & - & 30 & 7,5 \\
\hline Astyanax altiparanae & 305 & 26,8 & - & - & 9 & 2,3 \\
\hline Astyanax fasciatus & 323 & 28,4 & 11 & 7,7 & 18 & 4,5 \\
\hline Astyanax paranae ${ }^{1}$ & 96 & 8,4 & - & - & - & - \\
\hline Astyanax sp. 1 & 5 & 0,4 & 3 & 2,1 & - & - \\
\hline Astyanax sp. 2 & - & - & - & - & 6 & 1,5 \\
\hline Bryconamericus stramineus & - & - & 85 & 59,4 & - & - \\
\hline Cetopsorhamdia iheringi & - & - & - & - & 3 & 0,8 \\
\hline Characidium fasciatum & - & - & - & - & 61 & 15,3 \\
\hline Characidium gomesi & 3 & 0,3 & - & - & - & - \\
\hline Characidium zebra & 31 & 2,7 & - & - & - & - \\
\hline Cheirodon stenodon & - & - & - & - & 2 & 0,5 \\
\hline Corydoras difluviatilis $^{2}$ & 3 & 0,3 & - & - & - & - \\
\hline Crenicichla britskii & - & - & 1 & 0,7 & 5 & 1,3 \\
\hline Eigenmannia virescens & 2 & 0,2 & - & - & 23 & 5,8 \\
\hline Gymnotus carapo & 13 & 1,1 & - & - & 2 & 0,5 \\
\hline Hisonotus francirochai & 8 & 0,7 & 10 & 7,0 & 90 & 22,6 \\
\hline Hisonotus insperatus & - & - & 1 & 0,7 & - & - \\
\hline Hoplias malabaricus & 4 & 0,4 & - & - & - & - \\
\hline Hypostomus ancistroides & 37 & 3,3 & 12 & 8,4 & - & - \\
\hline Hypostomus nigromaculatus & - & - & 6 & 4,2 & - & - \\
\hline Hypostomus sp. & - & - & - & - & 10 & 2,5 \\
\hline Imparfinis mirini & 5 & 0,4 & 1 & 0,7 & 3 & 0,8 \\
\hline Imparfinis schubarti & - & - & - & - & 1 & 0,3 \\
\hline Leporinus striatus & - & - & - & - & 2 & 0,5 \\
\hline Moenkhausia sanctaefilomenae & - & - & - & - & 6 & 1,5 \\
\hline Oligosarcus pintoi & 9 & 0,8 & - & - & 6 & 1,5 \\
\hline Phalloceros caudimaculatus & 232 & 20,4 & 10 & 7,0 & - & - \\
\hline Piabina argentea & - & - & - & - & 57 & 14,3 \\
\hline Pimelodella avanhandavae & - & - & - & - & 46 & 11,6 \\
\hline Pimelodella sp. & 1 & 0,1 & - & - & - & - \\
\hline Pyrrhulina australis & - & - & - & - & 7 & 1,8 \\
\hline Rhamdia quelen & 48 & 4,2 & 2 & 1,4 & 1 & 0,3 \\
\hline Rhamdiopsis sp. & 3 & 0,3 & 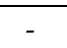 & - & 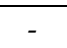 & $\overline{-}$ \\
\hline Serrapinnus notomelas & - & - & - & - & 6 & 1,5 \\
\hline Steindachnerina insculpta & - & - & - & - & 1 & 0,3 \\
\hline Synbranchus marmoratus & - & - & - & - & 3 & 0,8 \\
\hline Tatia neivai & - & - & 1 & 0,7 & - & - \\
\hline Trichomycterus sp. & 9 & 0,8 & - & - & - & - \\
\hline Abundância total & 1.137 & 100 & 143 & 100 & 398 & 100 \\
\hline
\end{tabular}

1. Espécie mencionada como Astyanax scabripinnis no estudo de Castro \& Casatti (1997)

2. Espécie mencionada como Corydoras aff. cochui no estudo de Castro \& Casatti (1997) 
Tabela 2. Descrição das categorias de integridade biótica empregadas no presente estudo (adaptadas a partir de Roth et al. 1999). Table 2. Description of the biotic integrity categories applied to the present study (adapted from Roth et al. 1999).

\begin{tabular}{|c|c|c|}
\hline Categoria & Valor numérico & Descrição \\
\hline Bom & $4,0-5,0$ & $\begin{array}{l}\text { Comparável aos riachos referência e considerados minimamente } \\
\text { impactados. Em média, os atributos biológicos se enquadram acima } \\
\text { de } 75 \% \text { da condição referência. }\end{array}$ \\
\hline Regular & $3,0-3,9$ & $\begin{array}{l}\text { Comparável aos riachos-referência, porém com alguns aspectos da } \\
\text { biologia comprometidos. Em média, os atributos situam-se entre } 75 \\
\text { e } 50 \% \text { da condição referência. }\end{array}$ \\
\hline Pobre & $2,0-2,9$ & $\begin{array}{l}\text { Significativo desvio da condição referência, com muitos aspectos da } \\
\text { integridade biológica distantes da situação minimamente impactada. } \\
\text { Em média, os atributos situam-se entre } 50 \text { e } 25 \% \text { da condição } \\
\text { referência. }\end{array}$ \\
\hline Muito pobre & $0-1,9$ & $\begin{array}{c}\text { Forte desvio da condição referência, com muitos aspectos da } \\
\text { integridade biológica alterados, indicando degradação séria. A } \\
\text { maioria dos atributos biológicos está abaixo de } 25 \% \text { da condição } \\
\text { referência }\end{array}$ \\
\hline
\end{tabular}




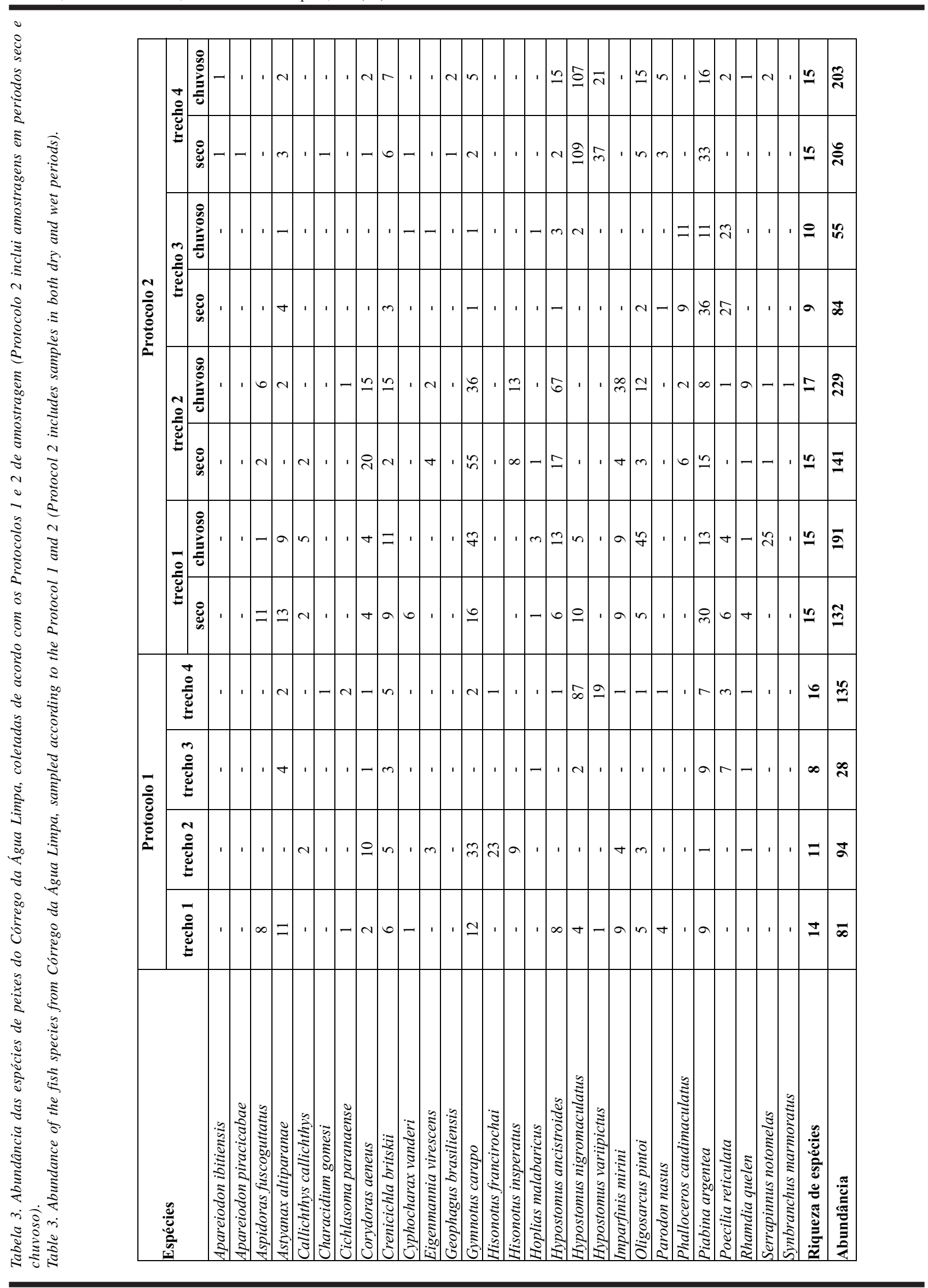


Tabela 4. Grupos tróficos das espécies registradas no Córrego da Água Limpa. *Quando menos de cinco exemplares foram examinados, são mencionados apenas os itens predominantes nos conteúdos gástricos.

Table 4. Trophic groups of the fish species registered in the Córrego da Água Limpa. *When less than five specimens were examined, only predominant items in each stomach were mentioned.

\begin{tabular}{|c|c|}
\hline Espécies & Grupos Tróficos / Itens predominantes \\
\hline Apareiodon ibitiensis* & Vegetais superiores e larvas de Chironomidae \\
\hline Apareiodon piracicabae* & Vegetais superiores \\
\hline Aspidoras fuscoguttatus & Insetívoro aquático generalista \\
\hline Astyanax altiparanae & Onívoro \\
\hline Callichthys callichthys & Onívoro \\
\hline Characidium gomesi* & Fragmentos de insetos aquáticos \\
\hline Cichlasoma paranaense* & Fragmentos de insetos aquáticos \\
\hline Corydoras aeneus & Insetívoro aquático generalista \\
\hline Crenicichla britskii & Insetívoro aquático generalista \\
\hline Cyphocharax vanderi & Detritívoro \\
\hline Eigenmannia virescens & Insetívoro aquático generalista \\
\hline Geophagus brasiliensis* & Fragmentos de insetos aquáticos \\
\hline Gymnotus carapo & Insetívoro aquático generalista \\
\hline Hisonotus francirochai & Detritívoro \\
\hline Hisonotus insperatus & Detritívoro \\
\hline Hoplias malabaricus* & Decápodes, hemípteros e peixes \\
\hline Hypostomus ancistroides & Detritívoro \\
\hline Hypostomus nigromaculatus & Detritívoro \\
\hline Hypostomus variipictus & Detritívoro \\
\hline Imparfinis mirini & Insetívoro aquático generalista \\
\hline Oligosarcus pintoi & Insetívoro generalista \\
\hline Parodon nasus & Algívoro \\
\hline Phalloceros caudimaculatus & Detritívoro \\
\hline Piabina argentea & Insetívoro aquático generalista \\
\hline Poecilia reticulata & Detritívoro \\
\hline Rhamdia quelen & Insetívoro aquático generalista \\
\hline Serrapinnus notomelas & Algívoro \\
\hline Synbranchus marmoratus* & Fragmento animal \\
\hline
\end{tabular}




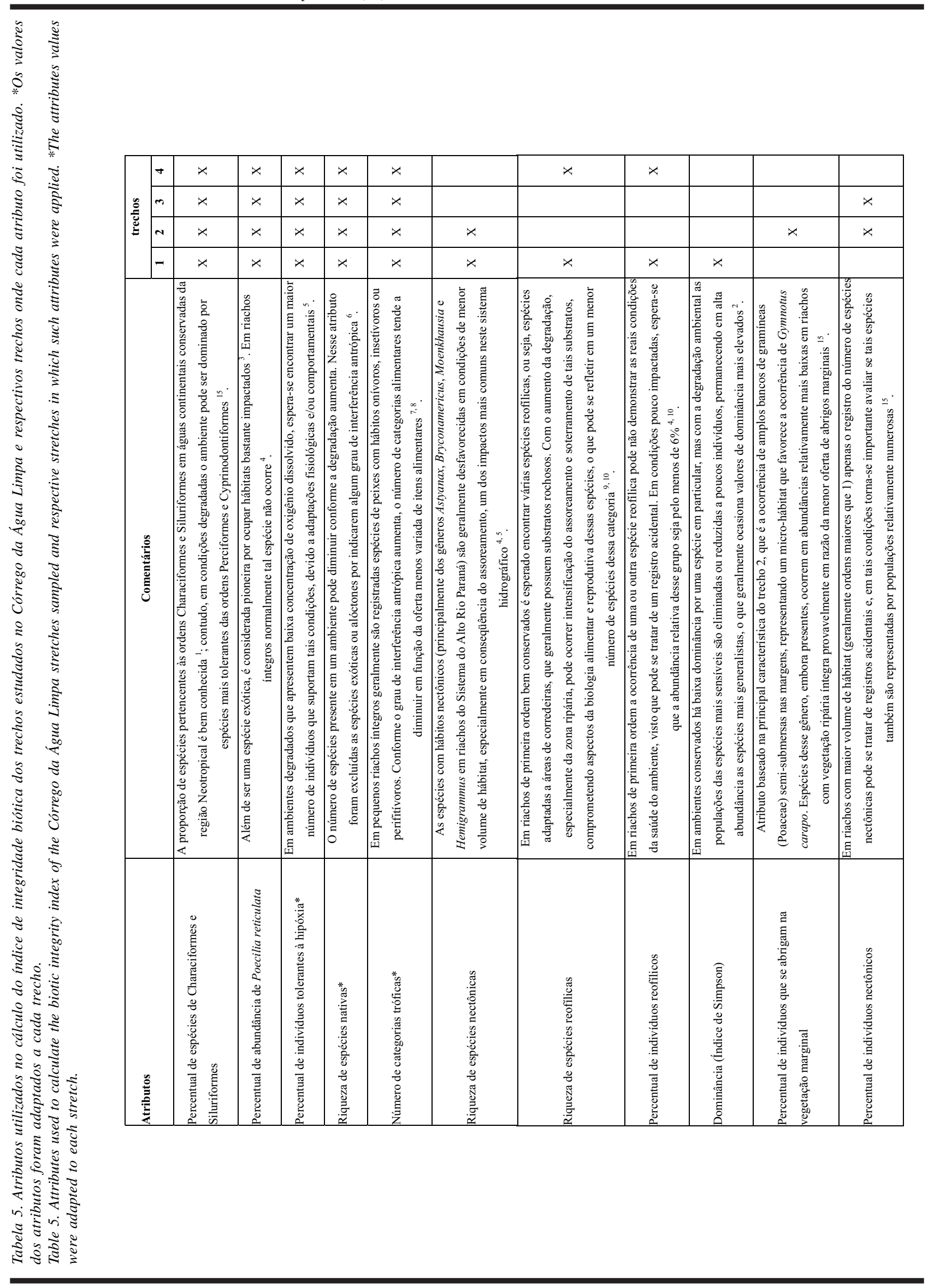

http://www.biotaneotropica.org.br 


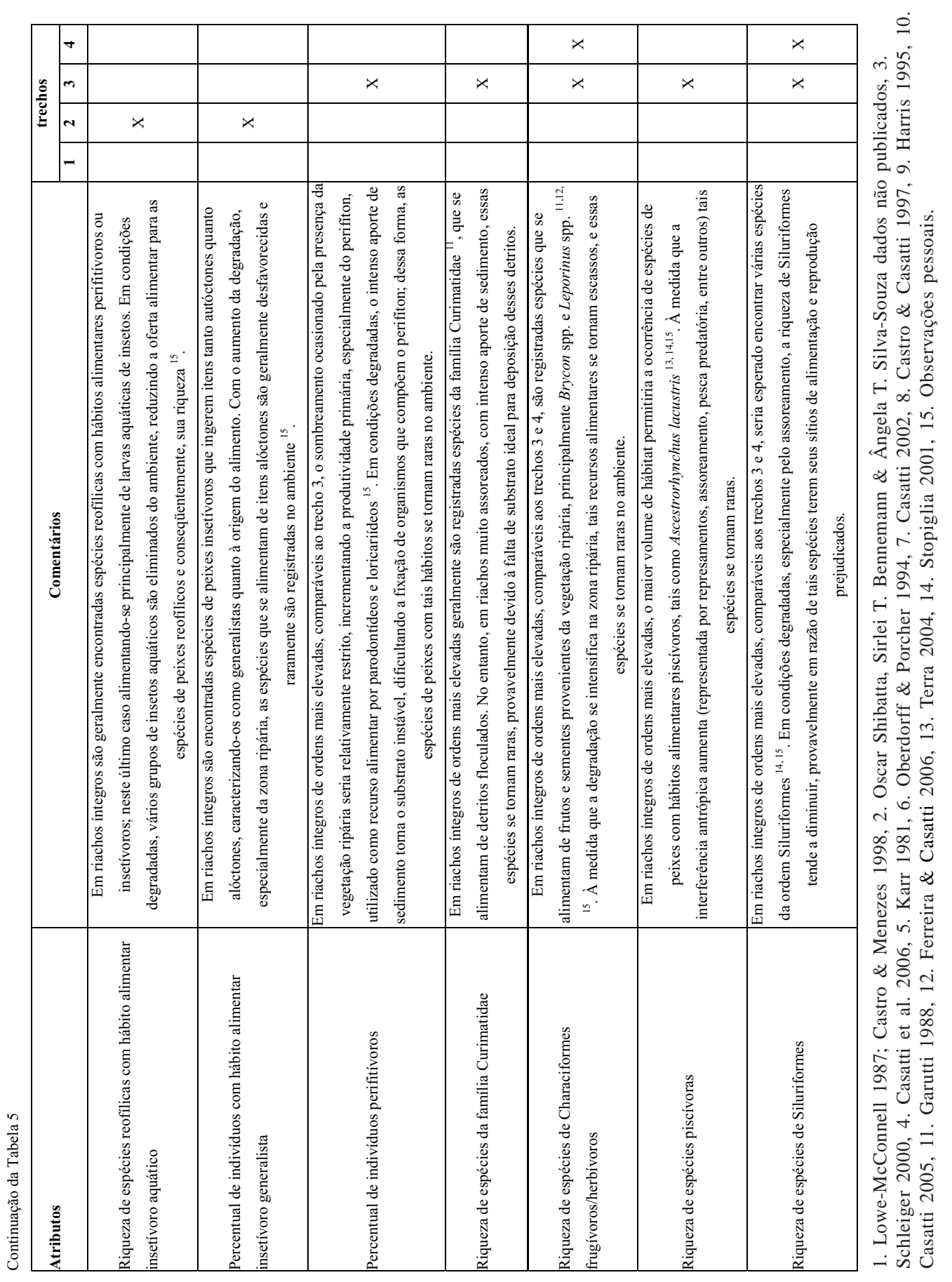


Tabela 6. Atributos biológicos e escores utilizados no Índice de Integridade Biótica para o trecho 1 do Córrego da Água Limpa. Table 6. Biological attributes and scores used in the Index of Biotic Integrity for the stretch 1 of the Córrego da Água Limpa.

\begin{tabular}{|l|c|c|c|}
\hline \multirow{2}{*}{ Atributos } & \multicolumn{3}{|c|}{ Escores } \\
\cline { 2 - 4 } & $\mathbf{5}$ & $\mathbf{3}$ & $\mathbf{1}$ \\
\hline Percentual de Characiformes e Siluriformes & $\mathrm{x} \geq 83$ & $76 \leq \mathrm{x}<83$ & $\mathrm{x}<76$ \\
\hline Percentual de abundância de Poecilia reticulata & $\mathrm{x}<6,3$ & $6,3 \leq \mathrm{x}<9$ & $\mathrm{x} \geq 9$ \\
\hline Percentual de indivíduos tolerantes à hipóxia & $\mathrm{x}<12$ & $12 \leq \mathrm{x}<16,3$ & $\mathrm{x} \geq 16,3$ \\
\hline Riqueza de espécies nativas & $\mathrm{x} \geq 12$ & $12<\mathrm{x} \leq 4$ & $\mathrm{x}<4$ \\
\hline Número de categorias tróficas & $\mathrm{x} \geq 4$ & $2<\mathrm{x}<3$ & $\mathrm{x}=1$ \\
\hline Riqueza de espécies nectônicas* & $\mathrm{x} \geq 3$ & $\mathrm{x}=2$ & $\mathrm{x}=1$ \\
\hline Riqueza de espécies reofílicas* & $\mathrm{x} \geq 3$ & $\mathrm{x}=2$ & $\mathrm{x}=1$ \\
\hline Percentual de indivíduos reofílicos & $\mathrm{x} \geq 3$ & $3<\mathrm{x} \leq 1$ & $\mathrm{x}<1$ \\
\hline Dominância & $\mathrm{x}<25$ & $25 \leq \mathrm{x}<35$ & $\mathrm{x} \geq 35$ \\
\hline
\end{tabular}

* atributo pontuado como zero quando tais espécies não foram registradas

Tabela 7. Atributos biológicos e escores utilizados no Índice de Integridade Biótica para o trecho 2 do Córrego da Água Limpa. Table 7. Biological attributes and scores used in the Index of Biotic Integrity for stretch 2 of the Córrego da Água Limpa.

\begin{tabular}{|l|c|c|c|}
\hline \multirow{2}{*}{ Atributos } & \multicolumn{2}{|c|}{ Escores } \\
\cline { 2 - 4 } & $\mathbf{5}$ & 3 \\
\hline Percentual de Characiformes e Siluriformes & $\mathrm{x} \geq 83$ & $76 \leq \mathrm{x}<83$ & $\mathrm{x}<76$ \\
\hline Percentual de abundância de Poecilia reticulata & $\mathrm{x}<6,3$ & $6,3 \leq \mathrm{x}<9$ & $\mathrm{x} \geq 9$ \\
\hline Percentual de indivíduos tolerantes à hipoxia & $\mathrm{x}<36$ & $50>\mathrm{x}>36$ & $\mathrm{x} \geq 50$ \\
\hline Riqueza de espécies nativas & $\mathrm{x} \geq 14$ & $5 \leq \mathrm{x}<14$ & $\mathrm{x}<5$ \\
\hline Número de categorias tróficas & $\mathrm{x} \geq 5$ & $2<\mathrm{x}<5$ & $\mathrm{x} \leq 2$ \\
\hline Riqueza de espécies nectônicas* & $\mathrm{x} \geq 3$ & $\mathrm{x}=2$ & $\mathrm{x}=1$ \\
\hline Percentual de indivíduos que se abrigam na vegetação marginal & $\mathrm{x}<2,5$ & $2,5 \leq \mathrm{x}<3,5$ & $\mathrm{X} \geq 3,5$ \\
\hline Percentual de indivíduos nectônicos & $\mathrm{x} \geq 48$ & $16 \leq \mathrm{x}<48$ & $\mathrm{x}<16$ \\
\hline Riqueza de espécies reofílicas com hábito alimentar insetívoro aquático* & $\mathrm{x} \geq 3$ & $\mathrm{x}=2$ & $\mathrm{x}=1$ \\
\hline Percentual de indivíduos com hábito alimentar insetívoro generalista & $\mathrm{x} \geq 5$ & $2 \leq \mathrm{x}<5$ & $\mathrm{x}<2$ \\
\hline
\end{tabular}

* atributo pontuado como zero quando tais espécies não foram registradas 
Tabela 8. Atributos biológicos e escores utilizados no Índice de Integridade Biótica para o trecho 3 do Córrego da Água Limpa. Table 8. Biological attributes and scores used in the Index of Biotic Integrity for stretch 3 of the Córrego da Água Limpa.

\begin{tabular}{|l|c|c|c|}
\hline \multirow{2}{*}{ Atributos } & \multicolumn{2}{|c|}{ Escores } \\
\cline { 2 - 4 } Percentual de Characiformes e Siluriformes & $\mathbf{5}$ & $\mathbf{3}$ & $\mathbf{1}$ \\
\hline Percentual de abundância de Poecilia reticulata & $\mathrm{x} \geq 83$ & $76 \leq \mathrm{x}<83$ & $\mathrm{x}<76$ \\
\hline Percentual de indivíduos tolerantes à hipóxia & $\mathrm{x}<6,3$ & $6,3 \leq \mathrm{x}<9$ & $\mathrm{x} \geq 9$ \\
\hline Riqueza de espécies nativas & $\mathrm{x}<36$ & $50>\mathrm{x} \geq 14$ & $\mathrm{x} \geq 50$ \\
\hline Número de categorias tróficas & $\mathrm{x}>9$ & $3<\mathrm{x} \leq 9$ & $\mathrm{x} \leq 3$ \\
\hline Percentual de indivíduos nectônicos & $\mathrm{x} \geq 4$ & $2 \leq \mathrm{x}<4$ & $\mathrm{x}<2$ \\
\hline Percentual de indivíduos perifitívoros & $\mathrm{x}>52$ & $17<\mathrm{x} \leq 52$ & $\mathrm{x} \leq 17$ \\
\hline Riqueza de espécies da família Curimatidae* & $\mathrm{x} \geq 9,5$ & $3<\mathrm{x}<9,5$ & $\mathrm{x} \leq 3$ \\
\hline Riqueza de espécies de Characiformes frugívoros/herbívoros* & $\mathrm{x}=3$ & $\mathrm{x}=2$ & $\mathrm{x}=1$ \\
\hline Riqueza de espécies piscívoras* & $\mathrm{x} \geq 3$ & $\mathrm{x}=2$ & $\mathrm{x}=1$ \\
\hline Riqueza de espécies de Siluriformes & $\mathrm{x} \geq 3$ & $\mathrm{x}=2$ & $\mathrm{x}=1$ \\
\hline
\end{tabular}

* atributo pontuado como zero quando tais espécies não foram registradas

Tabela 9. Atributos biológicos e escores utilizados no Índice de Integridade Biótica para o trecho 4 do Córrego da Água Limpa. Table 9. Biological attributes and scores used in the Index of Biotic Integrity for stretch 4 of the Córrego da Água Limpa.

\begin{tabular}{|l|c|c|c|}
\hline \multirow{2}{*}{ Atributos } & \multicolumn{2}{|c|}{ Escores } \\
\cline { 2 - 4 } & $\mathbf{5}$ & $\mathbf{3}$ & 1 \\
\hline Percentual de Characiformes e Siluriformes & $\mathrm{x} \geq 83$ & $76 \leq \mathrm{x}<83$ & $\mathrm{x}<76$ \\
\hline Percentual de abundância de Poecilia reticulata & $\mathrm{x}<6,3$ & $6,3 \leq \mathrm{x}<9$ & $\mathrm{x} \geq 9$ \\
\hline Percentual de indivíduos tolerantes à hipóxia & $\mathrm{x}<36$ & $50>\mathrm{x} \geq 36$ & $\mathrm{x} \geq 50$ \\
\hline Riqueza de espécies nativas & $\mathrm{x} \geq 18$ & $6<\mathrm{x}<18$ & $\mathrm{x} \leq 6$ \\
\hline Número de categorias tróficas & $\mathrm{x} \geq 5$ & $2 \leq \mathrm{x}<5$ & $\mathrm{x} \leq 2$ \\
\hline Riqueza de espécies reofílicas & $\mathrm{x} \geq 5$ & $2 \leq \mathrm{x}<5$ & $\mathrm{x}<2$ \\
\hline Percentual de indivíduos reofílicos & $\mathrm{x}>60$ & $20<\mathrm{x} \leq 60$ & $\mathrm{x} \leq 20$ \\
\hline Riqueza de espécies de Characiformes frugívoros/herbívoros* & $\mathrm{x} \geq 3$ & $\mathrm{x}=2$ & $\mathrm{x}=1$ \\
\hline Riqueza de espécies de Siluriformes & $\mathrm{x} \geq 6$ & $2<\mathrm{x}<6$ & $\mathrm{x} \leq 2$ \\
\hline
\end{tabular}

* atributo pontuado como zero quando tais espécies não foram registradas 


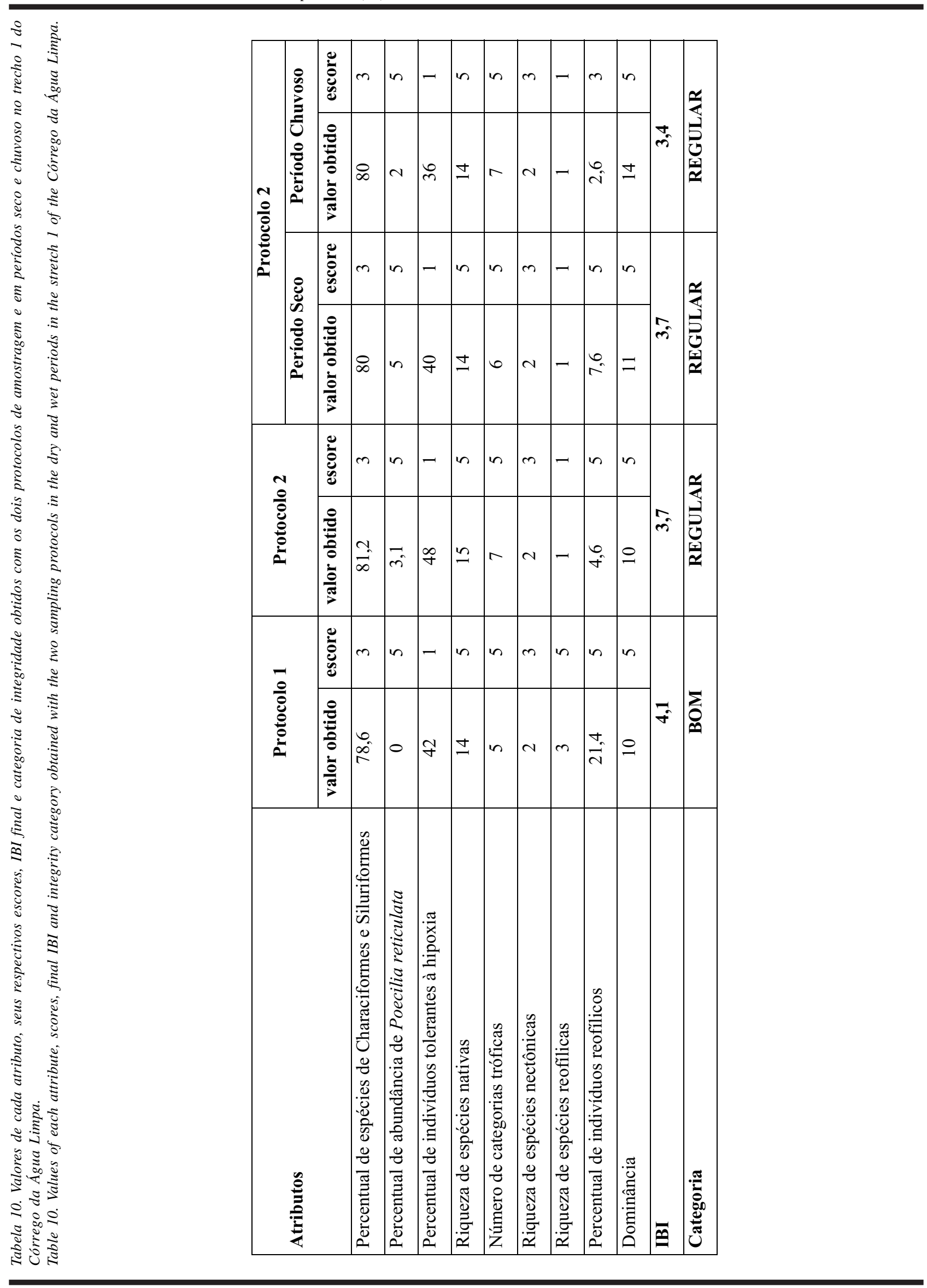

http://www.biotaneotropica.org.br 


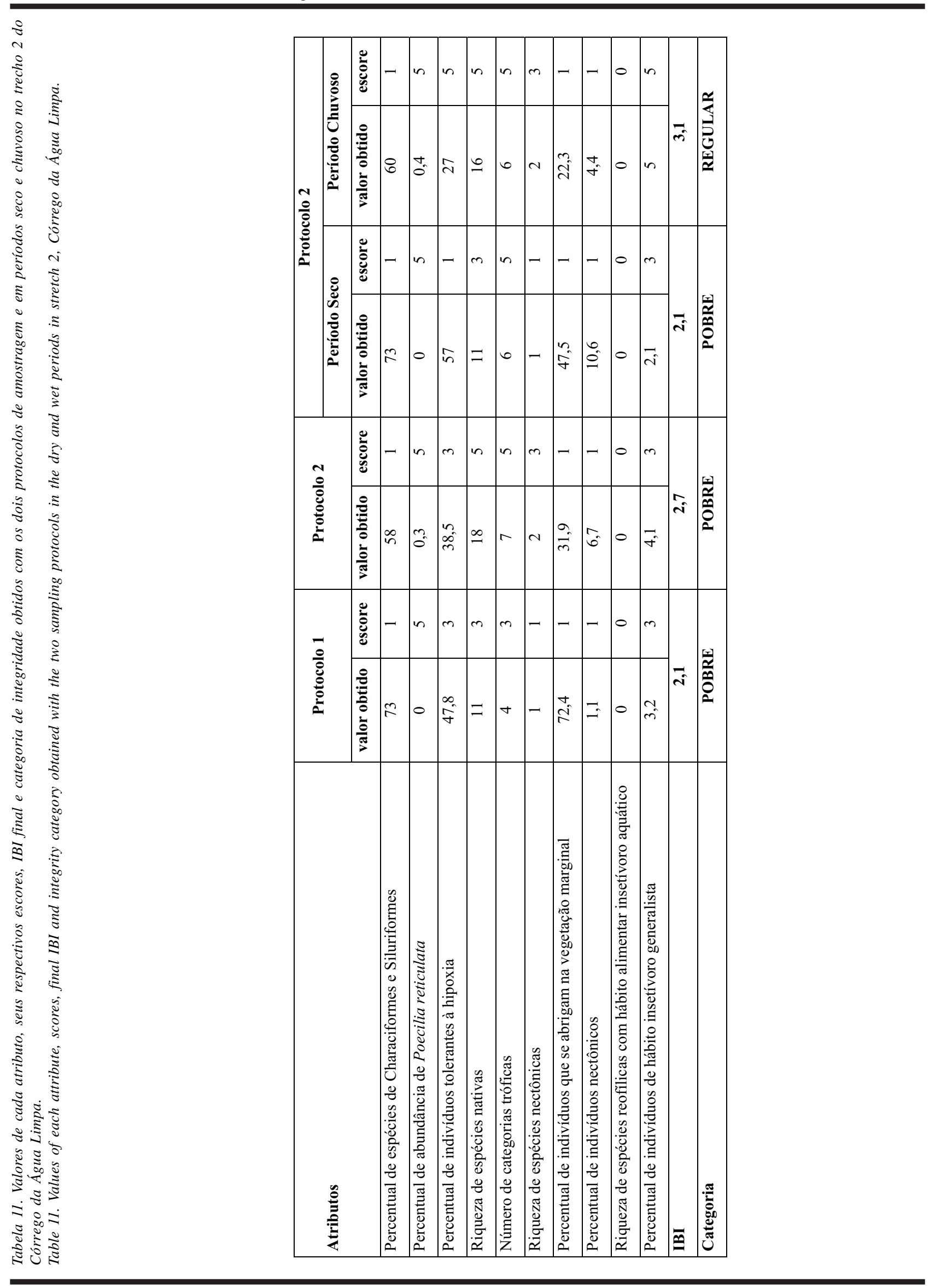

http://www.biotaneotropica.org.br 


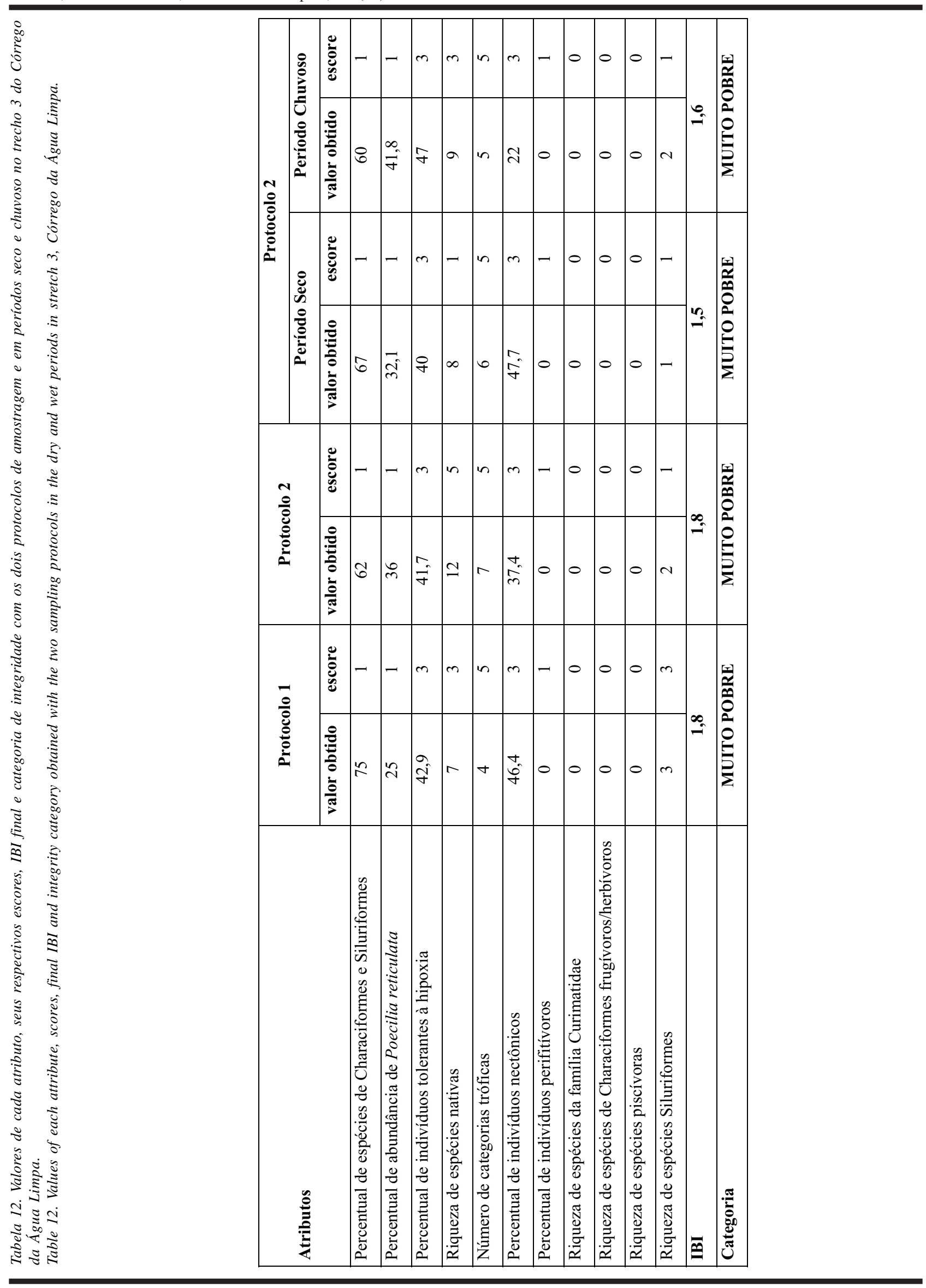

http://www.biotaneotropica.org.br 


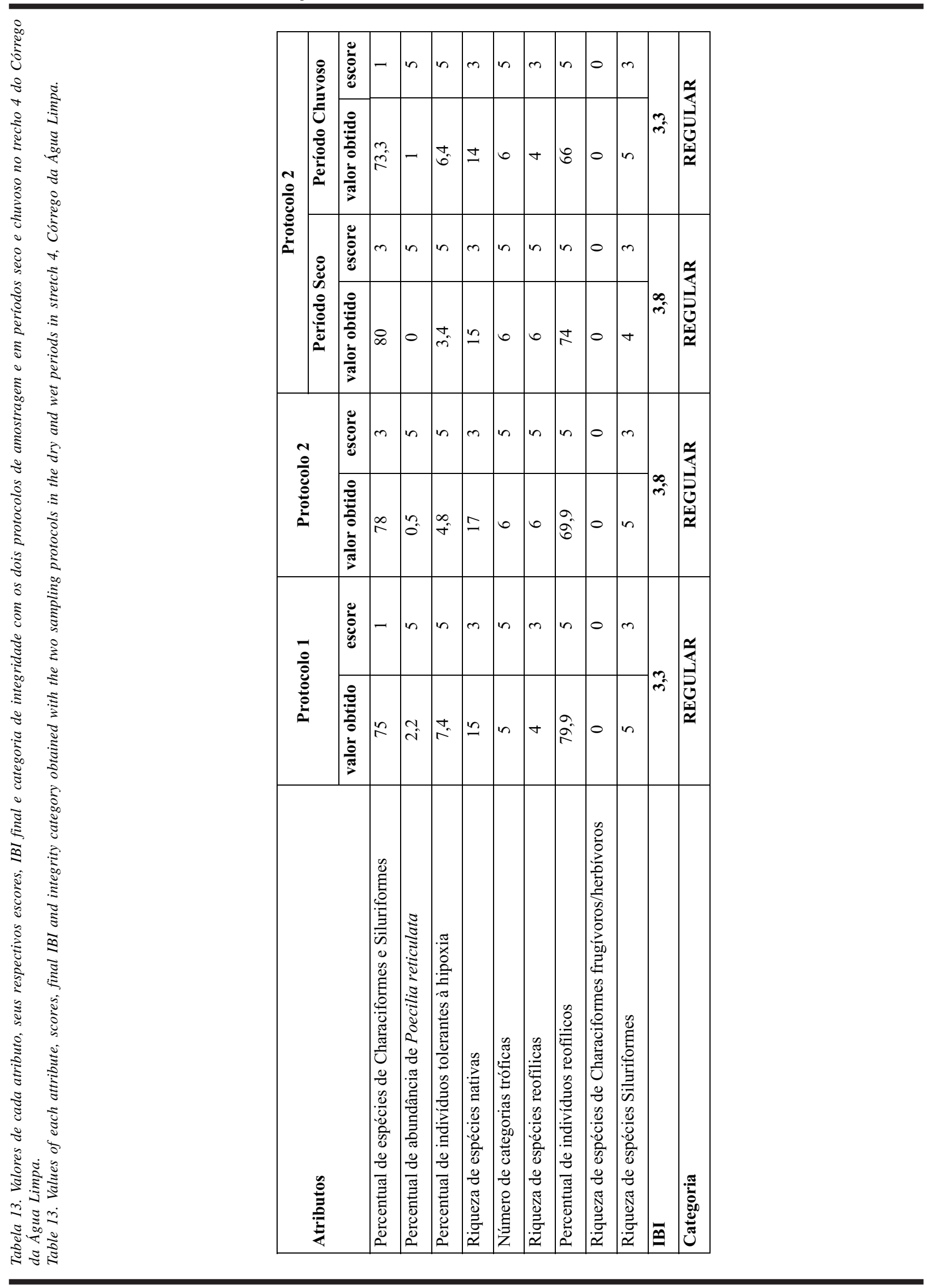

http://www.biotaneotropica.org.br 
Tabela 14. Índice de qualidade química da água para riachos (SWI, "Stream Water Index"), índice de integridade física do hábitat (PHI, "Physical Habitat Index") e índice de integridade biótica (IBI, "Index of Biotic Integrity”) calculado com diferentes métodos de amostragem e nos dois períodos do ano para os trechos estudados no Córrego da Água Limpa.

Table 14. Stream Water Index (SWI), Physical Habitat Integrity Index (PHI) and Index of Biotic Integrity (IBI) calculated applying different sampling methods in both seasons to the studied stretches of the Córrego da Água Limpa.

\begin{tabular}{|c|c|c|c|c|c|c|}
\hline \multirow{2}{*}{ Trechos } & SWI & PHI & IBI & IBI & IBI & IBI \\
& & & Protocolo 1* & Protocolo 2** & Período Seco** & Período Chuvoso** $^{*}$ \\
\hline $\mathbf{1}$ & Bom & Regular & Bom & Regular & Regular & Regular \\
\hline $\mathbf{2}$ & Regular & Pobre & Pobre & Pobre & Pobre & Regular \\
\hline $\mathbf{3}$ & Bom & Pobre & Muito pobre & Muito Pobre & Muito Pobre & Muito Pobre \\
\hline $\mathbf{4}$ & Bom & Regular & Regular & Regular & Regular & Regular \\
\hline
\end{tabular}

* duas passagens de pesca elétrica em 75 metros de extensão / 2 passes of eletrofishing in 75 meters long

** uma passagem de pesca elétrica em 60 metros de extensão / 1 pass of electrofishing in 60 meters long 